\title{
Uma proposta de ontologia para a Assistência Farmacêutica a partir das páginas da Revista Ciência \& Saúde Coletiva
}

\author{
An ontology of Pharmaceutical Services in the pages \\ of Journal Ciência \& Saúde Coletiva
}

\author{
Claudia Garcia Serpa Osorio-de-Castro (http://orcid.org/0000-0003-4875-7216) ${ }^{1}$ \\ Tatiana de Jesus Nascimento Ferreira (https://orcid.org/0000-0002-9857-9852) ${ }^{1}$ \\ Mario Jorge Sobreira da Silva (https://orcid.org/0000-0002-0477-8595) ${ }^{2}$ \\ Elaine Silva Miranda (https://orcid.org/0000-0002-6204-5023) ${ }^{3}$ \\ Cristiane Roberta dos Santos Teodoro (https://orcid.org/0000-0001-6147-0987) ${ }^{4}$ \\ Elaine Lazzaroni Moraes (https://orcid.org/0000-0002-7903-5550) ${ }^{2}$ \\ Elisangela da Costa Lima (https://orcid.org/0000-0002-0101-790X) ${ }^{5}$ \\ Cláudia Du Bocage Santos-Pinto (https://orcid.org/0000-0002-5478-4977) ${ }^{6}$
}

${ }^{1}$ Departamento de Política

de Medicamentos e

Assistência Farmacêutica,

Escola Nacional de Saúde

Pública Sergio Arouca,

Fundação Oswaldo Cruz.

R. Leopoldo Bulhões 1480,

Manguinhos. 21041-210

Rio de Janeiro RJ Brasil.

claudiaosorio.soc@

gmail.com

${ }^{2}$ Instituto Nacional do

Câncer José Alencar Gomes

da Silva. Rio de Janeiro RJ

Brasil.

${ }^{3}$ Departamento de

Farmácia e Administração

Farmacêutica, Faculdade

de Farmácia, Universidade

Federal Fluminense. Niterói

RJ Brasil.

${ }^{4}$ Instituto de Psiquiatria,

Universidade Federal do Rio

de Janeiro (UFRJ). Rio de

Janeiro RJ Brasil.

${ }^{5}$ Faculdade de Farmácia,

UFRJ. Rio de Janeiro RJ

Brasil.

${ }^{6}$ Instituto Integrado de

Saúde, Universidade Federal

de Mato Grosso do Sul.

Campo Grande MS Brasil.

\begin{abstract}
Pharmaceutical Services (PS) is a growing field which has established itself over the last 25 years in Brazil through scientific publications. This work investigates the evolution of the field in the Brazilian periodical Journal Ciência \& Saúde Coletiva. We conducted a scoping review of relevant literature produced in four separate periods (1996-2003, 2004-2010, 2011-2015, and 2016-2019). A search for articles that contained one or more of the pre-established key words in the title was performed by separate pairs of reviewers. The search resulted in 307 articles, 260 of which were included. The findings show that the number of publications increased steadily over the study period. The papers were predominantly open-topic and original articles and written in Portuguese. Most of the lead authors were from the South and Southeastern regions of Brazil and from public universities and Fiocruz. The predominant primary theme was medicine utilization (161 articles), followed by management (56), and tangential aspects of the PM cycle (43). An ontology of PS was created based on the classification of the articles. The findings show that the field of PS encompasses public policy and management and frontline activities involved in the delivery of health care to the population. It is hoped that the diverse range of interrelations in the field of PS will be increasingly addressed in future publications.
\end{abstract}

Key words Pharmaceutical Services, Publications, Review
Resumo A Assistência Farmacêutica (AF) é um campo em expansão no Brasil e nos últimos 25 anos vem se consolidando também através da publicação científica. O objetivo deste trabalho foi investigar a evolução da AF como campo na Revista Ciência e Saúde Coletiva. Uma revisão de escopo, em quatro períodos, 1996-2003, 2004-2010, 2011-2015, 2016-2019, foi realizada por duplas de pesquisadores, buscando palavras e termos de busca nos títulos. As inclusões foram totalizadas por ano de publicação, suas características descritas quanto ao tipo de artigo, idioma, local e instituição de origem do primeiro autor e classificadas por temáticas principais, secundárias e especificidades. Foram resgatados 307 artigos e incluídos 260. Os resultados refletiram aumento de publicações ao longo do tempo, participação majoritária de artigos de tema livre e originais, em português, de autores das regiões Sul e Sudeste, de universidades públicas e da Fiocruz. Os temas principais foram Utilização de Medicamentos (161 artigos), Gestão (56) e Temas Tangenciais ao Ciclo da AF (43). A partir da classificação foi elaborada uma ontologia própria da AF. O campo reúne política pública a atividades gerenciais e de cuidados em saúde à população. Espera-se que essa variada gama de interrelações venha a se expressar cada vez mais na publicação científica.

Palavras-chave Assistência Farmacêutica, Publicações, Revisão 


\section{Introdução}

A Assistência Farmacêutica (AF) é um campo teórico-prático relativamente recente dentro do escopo das Ciências Farmacêuticas, que, tradicionalmente foram moldadas pelas ciências ditas básicas, tais como física, química, bioquímica, fisiologia etc. As ciências básicas, por sua vez, caracterizaram a forma como a Farmácia foi ensinada e consequentemente o perfil dos profissionais atuantes na academia ou nos serviços assistenciais. Ao longo das últimas décadas, as questões sociais ligadas ao medicamento passaram a ter maior importância, visto que as ciências naturais, por si só, não são capazes de explicar ou aprofundar aspectos que envolvem a relação do medicamento com indivíduos, famílias, comunidades ou mesmo com a prática profissional ${ }^{1,2}$.

No Brasil, a Lei Orgânica da Saúde, que regula as ações e serviços de saúde, determina como campo de atuação do Sistema Único de Saúde (SUS), a formulação da política de medicamentos, e atribui ao setor saúde a responsabilidade pela execução de ações de assistência terapêutica integral, inclusive farmacêutica ${ }^{3}$. Entretanto, a $\mathrm{AF}$, só começa a ser efetivamente delineada a partir na publicação da Política Nacional de Medicamentos (PNM) em 19984. No que tange a gestão pública de medicamentos, em 1999 iniciou-se o processo de descentralização da Assistência Farmacêutica ${ }^{5}$, com definição das responsabilidades cabíveis a cada nível de gestão - ao federal a formulação e implementação da Política, ao estadual, primordialmente, coordenação, execução, acompanhamento e avaliação da Política, e ao municipal as funções primordiais de provisão ${ }^{3}$.

Outro marco estabelecido foi a Política Nacional de Assistência Farmacêutica (PNAF), no ano de 2004, que aponta para o profissional farmacêutico, no campo da AF, possibilidades de atuação na promoção, proteção e recuperação da saúde. Também direciona perspectivas de desenvolvimento da AF na inovação e produção de medicamentos e insumos, favorecendo a inclusão da Assistência Farmacêutica na Agenda Nacional de prioridades para pesquisas em saúde de $2004^{6}$.

Desde o início do estabelecimento da AF dentro do marco da PNM, foi adotado como modelo organizacional o "ciclo da AF". Desenvolvido em meados dos anos 1990 pelo Management Sciences for Health ${ }^{7}$, esse marco vem sendo revisitado ao longo do tempo, para refletir as mudanças do campo que impactariam na organização das atividades da $\mathrm{AF}^{8}$. Para o ciclo da AF, podem ser descritos três grandes núcleos de atividades: aqueles que antecedem o ciclo em si, tangenciais e envolvendo atores e atividades que extrapolam o campo da AF; as atividades de gestão; e as atividades relacionada à utilização dos medicamentos?.

Estima-se que a produção científica reflita os arcabouços político, normativo e técnico, não apenas nos momentos do desenvolvimento do campo, mas também na sua maturação técnica e no envolvimento profissional. Como parte integrante da Saúde Coletiva (SC), a AF tem em sua essência a articulação de saberes vinculados à prática nos serviços de saúde e engloba várias disciplinas das Ciências Farmacêuticas, mas com grande influência das ciências sociais ${ }^{10}$. A literatura vem apontando mudanças importantes na $\mathrm{AF}$ ao longo do tempo, refletindo sobre os grandes temas e sobre o papel da AF no SUS ${ }^{11}$.

Partindo do pressuposto de que os grandes temas da SC estão presentes na discussão do campo e na evolução do cenário da AF no Brasil, o presente artigo busca fazer uma análise da produção em assistência farmacêutica, pelas páginas da Revista Ciência \& Saúde Coletiva (RC\&SC), de forma a propor uma ontologia própria da $\mathrm{AF}$, inédita no campo.

\section{Métodos}

Foi realizada uma revisão de escopo do tema da AF na RC\&SC ${ }^{12,13}$. O período proposto de análise, de 1996 a 2019, foi dividido em quatro blocos temporais circundados por políticas importantes na área da $\mathrm{AF}^{4-6,14-20}$, e por volume de publicações, a saber, 1996-2003, 2004-2010, 2011-2015 e 2016-2019.

Cada bloco de tempo ficou ao encargo de uma dupla de pesquisadores para busca dos artigos pertinentes do campo da AF. A identificação foi feita de modo independente por cada indivíduo componente da dupla e depois em consenso, nas duplas e no grupo, para verificação e decisão sobre dúvidas ou inconsistências.

A identificação dos artigos, em cada número, foi feita a partir da página de RC\&SC. Na busca, levou-se em consideração a presença de um ou mais dos termos: assistência farmacêutica, medicamentos, política de medicamentos, farmacêuticos, setor farmacêutico, indústria farmacêutica, farmácia hospitalar, serviços farmacêuticos. Após identificação pelo título, resgatamos o texto completo através do sítio de internet do SciELO. Uma vez feita a identificação, foi feita a leitura dos resumos, na fase de verificação, de modo a estabelecer que estes termos também estavam presentes. 
Na fase de elegibilidade, a partir da leitura dos textos, foram excluídos aqueles artigos que tratavam de temas não afeitos diretamente à assistência farmacêutica ou à terapêutica medicamentosa. Destas exclusões resultou a seleção final de artigos para o estudo.

Para cada artigo selecionado, foram extraídas as seguintes informações: ano de publicação, autor(es), afiliação do autor principal e local, Digital Object Identifier (DOI), seção da publicação, tipo de artigo, resumo, palavras-chave. Foi formado um banco de dados organizado de forma sequencial, incluindo todos os artigos selecionados.

$\mathrm{Na}$ análise, o conjunto de artigos foi descrito a partir da linha de tempo, por número, autoria, local e afiliação do primeiro autor, idioma da publicação, tipo de artigo. As características temáticas dos artigos foram descritas por meio de categorização prévia, que considerou o racional da organização do campo que é utilizada no Brasil ${ }^{8,9,21}$. Os trabalhos foram classificados por uma temática principal (delimitadas inicialmente como Aspectos tangenciais ao Ciclo da AF; Gestão; e Utilização), uma temática secundária (aspecto da temática principal, que pode se configurar como atividade, condução normativa ou discussão conceitual) e uma especificidade (tema de fundo, que pode refletir objeto ou lócus da investigação). Foi feito esforço no sentido de explicitar as relações de dependência entre as temáticas principais, as temáticas secundárias e as especificidades, de modo a formar uma ontologia própria da AF nas páginas da RC\&SC.

\section{Resultados}

Foram recuperados 307 artigos, retornados da busca após leitura de títulos (Figura 1). Uma vez feita a leitura dos resumos, foram excluídos 47 trabalhos acerca de políticas de saúde, gastos em saúde, alocação de recursos em saúde, financiamento em saúde, assistência à saúde, diagnósticos, toxicologia, práticas médicas, medicalização (não afeita necessariamente à terapêutica medicamentosa), tabagismo, uso de drogas ilícitas, práticas contraceptivas não medicamentosas, materiais médico-hospitalares, terapias não medicamentosas, qualidade de vida e suplementação de nutrientes. Todos considerados não diretamente relacionadas ao tema da AF. Ao final foram incluídos 260 artigos (Quadro 1).

A busca envolveu o período compreendido entre o primeiro volume da Revista (1996) e o último de 2019. No entanto, no ano de 1996 não foi publicado artigo que estivesse dentro dos critérios de elegibilidade. Ao longo dos últimos 24 anos, as publicações no campo teórico-prático da AF tiveram considerável incremento, sobretudo a partir de 2008, como pode ser observado na Figura 2.

Em abril de 2008, foi lançado o primeiro número temático de medicamentos o que representou um aumento de 29 artigos. Desde então, a quantidade de publicações anuais no tema manteve-se entre 11 e 38 .

Embora o número de artigos apresentasse crescimento consistente no período, as características dos artigos mostraram-se variadas (Figura 3).

Em relação à tipologia (A), os artigos de tema livre foram os mais publicados, seguido pelos artigos originais (que segundo os critérios da Revista trata-se de trabalho empírico); este último tipo teve expressão principalmente entre 20042010 (37) e, também, entre 2016-2019 (25). Os totais da classificação 'temático' não refletem exatamente os números temáticos do campo (que ocorreram em 2008 e 2017). As revisões foram de pequena monta e as demais categorias não tiveram muito expressão. Os debates aconteceram nos anos em que houve publicação dos números temáticos.

Em relação ao idioma (B), a grande maioria dos trabalhos segue sendo publicada em português. Os trabalhos em inglês ou em ambos os idiomas parece ter maior expressão nos anos 2016-2019. A universidade pública foi o tipo de instituição de origem (C) que mais contribuiu ao tema na RC\&SC (141), em todos os anos examinados, seguido pela Fiocruz (48). As contribuições de ambas foram também crescendo ao longo do período. A universidade privada (35) e as instituições estrangeiras (10) diminuíram as contribuições ao longo do período. A Agência Nacional de Vigilância Sanitária contribuiu em 2004-2010 (6) e em 2011-2015 (1).

Da região Sudeste vieram a maioria dos primeiros autores dos artigos publicados (D), ao longo de todo o período, e as contribuições mostram-se crescentes. Em ordem decrescente em número de artigos, a região Sul, seguida de Nordeste e Centro-Oeste, apresentaram primeiros autores nas páginas da Revista, mas o número de artigos não cresceu no decorrer do tempo. A adesão de autores da Região Norte permanece um desafio, bem como de autores estrangeiros, cuja contribuição é modesta no tema dentro da Revista, tendo decrescido no último período (2016-2019). 


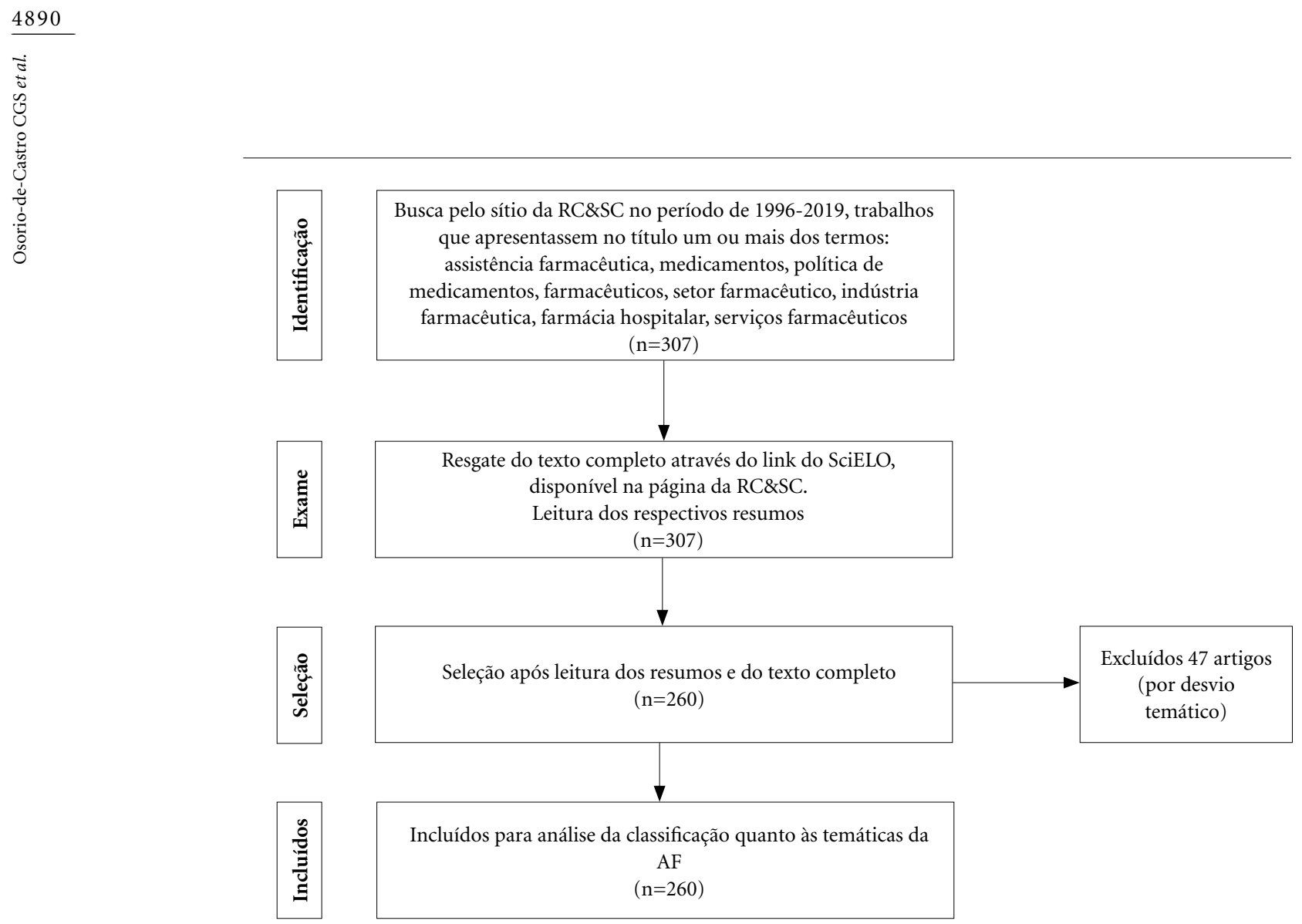

Figura 1. Fluxograma de seleção dos artigos publicados na Revista Ciência \& Saúde Coletiva, de 1996 a 2019, com destaque para o campo teórico-prático da Assistência Farmacêutica. RC\&SC, 2020.

Fonte. Elaboração própria, 2020.

Uma primeira abordagem quanto aos temas dos artigos veio da análise das palavras-chave. Os 260 artigo selecionados trouxeram 909 palavraschave. Eliminadas as duplicadas, permaneceram 550 palavras-chave. No entanto, 406 (74\%) apareceram apenas uma vez. As dez mais frequentes já existem como descritores: assistência farmacêutica (38), medicamento (sinonímia do descritor 'Preparações Farmacêuticas') (35), uso de medicamentos (23), Sistema único de Saúde (20), atenção primária em saúde (18), farmacoepidemiologia (17), vigilância sanitária (13), e idoso (12).

Os artigos mostraram-se distribuídos em três grandes temáticas principais estabelecidas pelo marco teórico da AF no Brasil ${ }^{7-9}$. A Figura 4 mostra a evolução ao longo do tempo.

A Figura 5 apresenta a distribuição das temáticas principais, em percentual, nos quatro períodos de observação. O grande tema Utiliza- ção foi consistentemente o mais frequente dentre as temáticas publicadas na RC\&SC ao longo de todo o tempo examinado e em todos os períodos, com 161 artigos. Gestão vem em segundo lugar como temática principal, com 56 artigos e temáticas tangenciais ao Ciclo da AF representaram 43 artigos no total.

Em relação às temáticas secundárias, sua variedade foi crescendo ao longo do tempo e por período. Temáticas secundárias foram também expressas sob diferentes temáticas principais, como pode ser observado na Figura 5.

A Figura 5 mostra que ao longo do tempo o escopo das publicações no campo torna-se cada vez mais complexo, com entrada de múltiplos temas secundários. A maior variedade está ligada ao grande tema utilização (A), com menor densidade entre 1996 e 2003, mas com aumento ao longo dos demais períodos. 
Quadro 1. Relação dos artigos selecionados para análise do campo teórico-prático da Assistência Farmacêutica nas páginas da Revista Ciência \& Saúde Coletiva, 1996-2019. RC\&SC, 2020.

\begin{tabular}{|c|c|c|c|c|c|c|}
\hline $\begin{array}{l}\text { Quan- } \\
\text { tidade }\end{array}$ & Ano & Idioma & $\begin{array}{c}\text { Local } \\
\text { (Estado } \\
\text { ou país) } \\
\end{array}$ & $1^{\circ}$ autor & Título & $\begin{array}{c}\text { Sessão da } \\
\text { publicação }\end{array}$ \\
\hline 1 & 1999 & POR & SP & Noto, AR & $\begin{array}{l}\text { O uso de drogas psicotrópicas e a prevenção no } \\
\text { Brasil }\end{array}$ & Revisão \\
\hline 2 & 1999 & POR & MS & Castro, LLC & $\begin{array}{l}\text { Farmacoepidemiologia no Brasil: evolução e } \\
\text { perspectivas }\end{array}$ & Opinião \\
\hline
\end{tabular}

\begin{tabular}{|l|l|l|l|l|l|l|}
\hline 3 & 2002 & POR & PE & Barros, JAC & $\begin{array}{l}\text { Anúncios de medicamentos em revistas médicas: } \\
\text { ajudando a promover a boa prescrição? }\end{array}$ & Original \\
\hline 4 & 2003 & POR & SC & Leite, SN & $\begin{array}{l}\text { Adesão à terapêutica medicamentosa: elementos para } \\
\text { a discussão de conceitos e pressupostos adotados na } \\
\text { literatura }\end{array}$ & Revisão \\
\hline
\end{tabular}

\begin{tabular}{|c|c|c|c|c|c|c|}
\hline 5 & 2003 & POR & RJ & Silva, LK & $\begin{array}{l}\text { Avaliação tecnológica e análise custo-efetividade em } \\
\text { saúde: a incorporação de tecnologias e a produção } \\
\text { de diretrizes clínicas para o SUS }\end{array}$ & Original \\
\hline 6 & 2004 & POR & SP & Pereira, LRL & $\begin{array}{l}\text { Avaliação da utilização de medicamentos em } \\
\text { pacientes idosos por meio de conceitos de } \\
\text { farmacoepidemiologia e farmacovigilância }\end{array}$ & Tema Livre \\
\hline 7 & 2004 & POR & RJ & $\begin{array}{l}\text { Osorio-de-Castro, } \\
\text { CGS }\end{array}$ & O uso de medicamentos na gravidez & Tema Livre \\
\hline 8 & 2005 & POR & RJ & Nascimento, MC & Medicamentos, comunicação e cultura & Original \\
\hline 9 & 2005 & POR & SP & Secoli, SR & $\begin{array}{l}\text { Farmacoeconomia: perspectiva emergente no } \\
\text { processo de tomada de decisão }\end{array}$ & Original \\
\hline 10 & 2007 & POR & $\mathrm{DF}$ & Fagundes, MJD & $\begin{array}{l}\text { Análise bioética da propaganda e publicidade de } \\
\text { medicamentos }\end{array}$ & Tema Livre \\
\hline 11 & 2007 & POR & PR & Melo, EB & $\begin{array}{l}\text { Histórico das tentativas de liberação da venda de } \\
\text { medicamentos em estabelecimentos leigos no Brasil } \\
\text { a partir da implantação do Plano Real }\end{array}$ & Opinião \\
\hline 12 & 2007 & POR & RJ & Neves, BG & $\begin{array}{l}\text { Percepções e atitudes de responsáveis por crianças } \\
\text { frente ao uso de medicamentos infantis e sua relação } \\
\text { com cárie e erosão dentária }\end{array}$ & Original \\
\hline 13 & 2008 & POR & DF & Bortolon, PC & $\begin{array}{l}\text { Análise do perfil de automedicação em mulheres } \\
\text { idosas brasileiras }\end{array}$ & Original \\
\hline 14 & 2008 & POR & $\mathrm{RJ}$ & Costa-Couto, $\mathrm{MH}$ & $\begin{array}{l}\text { Assimetria nas relações internacionais, propriedade } \\
\text { industrial e medicamentos anti-aids }\end{array}$ & Original \\
\hline 15 & 2008 & POR & MG & Abrantes, PM & $\begin{array}{l}\text { A qualidade da prescrição de antimicrobianos em } \\
\text { ambulatórios públicos da Secretaria Municipal de } \\
\text { Saúde de Belo Horizonte, MG }\end{array}$ & Original \\
\hline 16 & 2008 & POR & RJ & Alves, NDC & $\begin{array}{l}\text { Avaliação da adequação técnica de indústrias de } \\
\text { medicamentos fitoterápicos e oficinais do Estado do } \\
\text { Rio de Janeiro }\end{array}$ & Original \\
\hline 17 & 2008 & POR & MG & Angonesi, D & $\begin{array}{l}\text { Dispensação farmacêutica: uma análise de diferentes } \\
\text { conceitos e modelos }\end{array}$ & Original \\
\hline 18 & 2008 & POR & PE & Aquino, DS & $\begin{array}{l}\text { Por que o uso racional de medicamentos deve ser } \\
\text { uma prioridade? }\end{array}$ & Original \\
\hline 19 & 2008 & POR & MG & Araújo, ALA & $\begin{array}{l}\text { Perfil da assistência farmacêutica na atenção } \\
\text { primária do Sistema Único de Saúde }\end{array}$ & Original \\
\hline 20 & 2008 & SPN & MG & Barros, JAC & Nuevas tendencias de la medicalización & Original \\
\hline 21 & 2008 & POR & RJ & Rozenfeld, S & Farmacêutico: profissional de saúde e cidadão & Debate \\
\hline 22 & 2008 & POR & MG & Barros, JAC & $\begin{array}{l}\text { Comentário ao texto "Farmacêutico: profissional de } \\
\text { saúde e cidadão }\end{array}$ & Debate \\
\hline 23 & 2008 & POR & SP & $\begin{array}{l}\text { Bergsten-Mendes, } \\
\text { G }\end{array}$ & $\begin{array}{l}\text { Uso racional de medicamentos: o papel fundamental } \\
\text { do farmacêutico }\end{array}$ & Debate \\
\hline
\end{tabular}


Quadro 1. Relação dos artigos selecionados para análise do campo teórico-prático da Assistência Farmacêutica nas páginas da Revista Ciência \& Saúde Coletiva, 1996-2019. RC\&SC, 2020.

\begin{tabular}{|c|c|c|c|c|c|c|}
\hline $\begin{array}{l}\text { Quan- } \\
\text { tidade }\end{array}$ & Ano & Idioma & $\begin{array}{c}\text { Local } \\
\text { (Estado } \\
\text { ou país) }\end{array}$ & $1^{\circ}$ autor & Título & $\begin{array}{l}\text { Sessão da } \\
\text { publicação }\end{array}$ \\
\hline 24 & 2008 & POR & RJ & $\begin{array}{l}\text { Osorio-de-Castro, } \\
\text { CGS }\end{array}$ & $\begin{array}{l}\text { Farmacêutico: ser profissional de saúde e cidadão } \\
\text { exige responsabilização }\end{array}$ & Debate \\
\hline 25 & 2008 & POR & RJ & Elda Falqueto, E & $\begin{array}{l}\text { Gerenciamento de resíduos oriundos da fabricação } \\
\text { e distribuição do medicamento Diazepam para o } \\
\text { município de São Mateus, ES }\end{array}$ & Original \\
\hline 26 & 2008 & POR & SP & Fleith, VD & $\begin{array}{l}\text { Perfil de utilização de medicamentos em usuários da } \\
\text { rede básica de saúde de Lorena, SP }\end{array}$ & Original \\
\hline 27 & 2008 & POR & SP & Huertas, MKZ & $\begin{array}{l}\text { Apelos racionais e emocionais na propaganda de } \\
\text { medicamentos de prescrição: estudo de um remédio } \\
\text { para emagrecer }\end{array}$ & Original \\
\hline 28 & 2008 & POR & SC & Kulkamp, IC & $\begin{array}{l}\text { Percepção de profissionais da saúde sobre aspectos } \\
\text { relacionados à dor e utilização de opióides: um } \\
\text { estudo qualitativo }\end{array}$ & Original \\
\hline 29 & 2008 & POR & $\mathrm{DF}$ & Mota, DM & $\begin{array}{l}\text { Uso racional de medicamentos: uma abordagem } \\
\text { econômica para tomada de decisões }\end{array}$ & Original \\
\hline 30 & 2008 & POR & SP & Nicolini, P & $\begin{array}{l}\text { Fatores relacionados à prescrição médica de } \\
\text { antibióticos em farmácia pública da região Oeste da } \\
\text { cidade de São Paulo }\end{array}$ & Original \\
\hline 31 & 2008 & POR & RJ & $\begin{array}{l}\text { Cristiane Quental, } \\
\text { C }\end{array}$ & $\begin{array}{l}\text { Medicamentos genéricos no Brasil: impactos das } \\
\text { políticas públicas sobre a indústria nacional }\end{array}$ & Original \\
\hline 32 & 2008 & POR & DF & Reis, AMM & $\begin{array}{l}\text { Desabastecimento de medicamentos: determinantes, } \\
\text { conseqüências e gerenciamento }\end{array}$ & Original \\
\hline 33 & 2008 & POR & $\mathrm{DF}$ & Carvalho, PB & $\begin{array}{l}\text { Rotulagem de suplementos vitamínicos e minerais: } \\
\text { uma revisão das normas federais }\end{array}$ & Revisão \\
\hline 34 & 2008 & POR & SC & Leite, SN & $\begin{array}{l}\text { Estudos de utilização de medicamentos: uma síntese } \\
\text { de artigos publicados no Brasil e América Latina }\end{array}$ & Revisão \\
\hline 35 & 2008 & POR & RJ & Loyola, MA & $\begin{array}{l}\text { Medicamentos e saúde pública em tempos de AIDS: } \\
\text { metamorfoses de uma política dependente }\end{array}$ & Revisão \\
\hline 36 & 2008 & POR & RS & Rocha, CH & $\begin{array}{l}\text { Adesão à prescrição médica em idosos de Porto } \\
\text { Alegre, RS }\end{array}$ & Original \\
\hline 37 & 2008 & POR & $\mathrm{PE}$ & Silva, RA & $\begin{array}{l}\text { Fatores associados à automedicação em dor } \\
\text { de dente: análise a partir dos profissionais dos } \\
\text { estabelecimentos farmacêuticos da cidade do Recife, } \\
\text { PE }\end{array}$ & Original \\
\hline 38 & 2008 & POR & RJ & Soares, JCRS & $\begin{array}{l}\text { "Quando o anúncio é bom, todo mundo compra." } \\
\text { O Projeto MonitorAÇÃO e a propaganda de } \\
\text { medicamentos no Brasil }\end{array}$ & Original \\
\hline 39 & 2008 & POR & RS & Vitor, RS & $\begin{array}{l}\text { Padrão de consumo de medicamentos sem } \\
\text { prescrição médica na cidade de Porto Alegre, RS }\end{array}$ & Original \\
\hline 40 & 2008 & ENG/POR & RJ & Rozenfeld, S & Medicamentos, profissionais e atenção a saúde & Editorial \\
\hline 41 & 2008 & POR & MT & Reiners, AAO & $\begin{array}{l}\text { Produção bibliográfica sobre adesão/não-adesão de } \\
\text { pessoas ao tratamento de saúde }\end{array}$ & Revisão \\
\hline 42 & 2009 & ENG/POR & RJ & Nascimento, AC & $\begin{array}{l}\text { Propaganda de medicamentos no Brasil. É possível } \\
\text { regular? }\end{array}$ & Original \\
\hline 43 & 2009 & ENG & RJ & Emmerick, ICM & $\begin{array}{l}\text { Pharmaceutical services evaluation in Brazil: } \\
\text { broadening the results of a WHO methodology }\end{array}$ & Tema Livre \\
\hline 44 & 2010 & POR & DF & Polejack, L & $\begin{array}{l}\text { Monitoramento e avaliação da adesão ao } \\
\text { tratamento antirretroviral para HIV/aids: desafios e } \\
\text { possibilidades }\end{array}$ & \\
\hline 45 & 2010 & POR & RS & Rodrigues, FA & $\begin{array}{l}\text { Perfil da utilização de antimicrobianos em um } \\
\text { hospital privado }\end{array}$ & Original \\
\hline
\end{tabular}


Quadro 1. Relação dos artigos selecionados para análise do campo teórico-prático da Assistência Farmacêutica nas páginas da Revista Ciência \& Saúde Coletiva, 1996-2019. RC\&SC, 2020.

\begin{tabular}{|c|c|c|c|c|c|c|}
\hline $\begin{array}{l}\text { Quan- } \\
\text { tidade }\end{array}$ & Ano & Idioma & $\begin{array}{c}\text { Local } \\
\text { (Estado } \\
\text { ou país) }\end{array}$ & $1^{\circ}$ autor & Título & $\begin{array}{l}\text { Sessão da } \\
\text { publicação }\end{array}$ \\
\hline 46 & 2010 & POR & $\mathrm{CE}$ & Torres, DVM & $\begin{array}{l}\text { Enfuvirtida para o tratamento do paciente com aids: } \\
\text { o divisor de águas }\end{array}$ & \\
\hline 47 & 2010 & POR & RJ & Falqueto, E & $\begin{array}{l}\text { Como realizar o correto descarte de resíduos de } \\
\text { medicamentos? }\end{array}$ & Tema Livre \\
\hline 48 & 2010 & POR & MG & Angonesi, D & $\begin{array}{l}\text { Atenção Farmacêutica: fundamentação conceitual e } \\
\text { crítica para um modelo brasileiro }\end{array}$ & Tema Livre \\
\hline 49 & 2010 & POR & RJ & Bastos, CRG & $\begin{array}{l}\text { As percepções dos farmacêuticos sobre seu trabalho } \\
\text { nas farmácias comunitárias em uma região do estado } \\
\text { do Rio de Janeiro }\end{array}$ & Tema Livre \\
\hline 50 & 2010 & POR & SP & Cintra, FA & $\begin{array}{l}\text { Adesão medicamentosa em idosos em seguimento } \\
\text { ambulatorial }\end{array}$ & Tema Livre \\
\hline 51 & 2010 & POR & $\mathrm{DF}$ & Gava, CM & $\begin{array}{l}\text { Novos medicamentos registrados no Brasil: podem } \\
\text { ser considerados como avanço terapêutico? }\end{array}$ & Original \\
\hline 52 & 2010 & POR & PR & Knappmann, AL & $\begin{array}{l}\text { Qualidade de medicamentos isentos de prescrição: } \\
\text { um estudo com marcas de dipirona comercializadas } \\
\text { em uma drogaria de Cascavel (PR, Brasil) }\end{array}$ & Tema Livre \\
\hline 53 & 2010 & POR & $\mathrm{RJ}$ & Lago, RF & $\begin{array}{l}\text { Dilemas da política de distribuição de medicamentos } \\
\text { antirretrovirais no Brasil }\end{array}$ & Tema Livre \\
\hline 54 & 2010 & POR & PI & Lima, GB & $\begin{array}{l}\text { Uso de medicamentos armazenados em domicílio } \\
\text { em uma população atendida pelo Programa Saúde } \\
\text { da Família }\end{array}$ & Tema Livre \\
\hline 55 & 2010 & POR & SE & Lyra, DPJ & $\begin{array}{l}\text { Influência da propaganda na utilização de } \\
\text { medicamentos em um grupo de idosos atendidos em } \\
\text { uma unidade básica de saúde em Aracaju (SE, Brasil) }\end{array}$ & Tema Livre \\
\hline 56 & 2010 & POR & $\mathrm{RJ}$ & Nascimento, AC & $\begin{array}{l}\text { Propaganda de medicamentos para grande público: } \\
\text { parâmetros conceituais de uma prática produtora de } \\
\text { risco }\end{array}$ & Original \\
\hline 57 & 2010 & POR & BA & Oliveira, LCF & $\begin{array}{l}\text { Assistência Farmacêutica no Sistema Único de } \\
\text { Saúde: da Política Nacional de Medicamentos à } \\
\text { Atenção Básica à Saúde }\end{array}$ & Tema Livre \\
\hline 58 & 2010 & POR & SC & Pereira, JR & $\begin{array}{l}\text { Análise das demandas judiciais para o fornecimento } \\
\text { de medicamentos pela Secretaria de Estado da Saúde } \\
\text { de Santa Catarina nos anos de } 2003 \text { e } 2004\end{array}$ & Tema Livre \\
\hline 59 & 2010 & POR & $\mathrm{PB}$ & Portela, AS & $\begin{array}{l}\text { Prescrição médica: orientações adequadas para o uso } \\
\text { de medicamentos? }\end{array}$ & Tema Livre \\
\hline 60 & 2010 & POR & PA & Sebastião, PCA & $\begin{array}{l}\text { A visão de distintos atores sobre o controle sanitário } \\
\text { da importação de substâncias psicotrópicas no Brasil }\end{array}$ & Original \\
\hline 61 & 2010 & POR & $\mathrm{RJ}$ & Silva, ACP & $\begin{array}{l}\text { Desafios para a rede nacional de laboratórios de } \\
\text { vigilância sanitária: o caso dos medicamentos } \\
\text { manipulados }\end{array}$ & Original \\
\hline 62 & 2010 & POR & RS & Souza, MV & $\begin{array}{l}\text { Medicamentos de alto custo para doenças raras no } \\
\text { Brasil: o exemplo das doenças lisossômicas }\end{array}$ & Revisão \\
\hline 63 & 2010 & POR & SC & Trevisol, DJ & $\begin{array}{l}\text { A propaganda de medicamentos em escola de } \\
\text { medicina do Sul do Brasil }\end{array}$ & Tema Livre \\
\hline 64 & 2010 & POR & $\mathrm{DF}$ & Mota, DM & $\begin{array}{l}\text { Uso abusivo de benzidamina no Brasil: uma } \\
\text { abordagem em farmacovigilância }\end{array}$ & Original \\
\hline 65 & 2010 & POR & $\mathrm{PE}$ & Aquino, DS & A automedicação e os acadêmicos da área de saúde & Tema Livre \\
\hline 66 & 2010 & POR & RJ & Pepe, VLE & $\begin{array}{l}\text { A judicialização da saúde e os novos desafios da } \\
\text { gestão da assistência farmacêutica }\end{array}$ & Original \\
\hline
\end{tabular}


Quadro 1. Relação dos artigos selecionados para análise do campo teórico-prático da Assistência Farmacêutica nas páginas da Revista Ciência \& Saúde Coletiva, 1996-2019. RC\&SC, 2020.

\begin{tabular}{|c|c|c|c|c|c|c|}
\hline $\begin{array}{l}\text { Quan- } \\
\text { tidade }\end{array}$ & Ano & Idioma & $\begin{array}{c}\text { Local } \\
\text { (Estado } \\
\text { ou país) }\end{array}$ & $1^{\circ}$ autor & Título & $\begin{array}{c}\text { Sessão da } \\
\text { publicação }\end{array}$ \\
\hline 67 & 2010 & POR & SC & Galato, D & $\begin{array}{l}\text { Estudo de utilização de medicamentos em idosos } \\
\text { residentes em uma cidade do sul de Santa Catarina } \\
\text { (Brasil): um olhar sobre a polimedicação }\end{array}$ & Tema Livre \\
\hline 68 & 2010 & POR & SE & Lyra, DPJ & $\begin{array}{l}\text { Bulas de medicamentos usados por idosos } \\
\text { com hipertensão: adequação da informação à } \\
\text { regulamentação sanitária e possíveis implicações } \\
\text { para a saúde }\end{array}$ & Original \\
\hline 69 & 2010 & POR & SP & Carvalho, VAP & $\begin{array}{l}\text { Nível de conhecimento dos cirurgiões-dentistas } \\
\text { de São José dos Campos sobre o uso de anti- } \\
\text { inflamatórios não esteróides }\end{array}$ & Original \\
\hline 70 & 2010 & POR & DF & Naves, JOS & $\begin{array}{l}\text { Automedicação: uma abordagem qualitativa de suas } \\
\text { motivações }\end{array}$ & Original \\
\hline 71 & 2010 & POR & DF & Leite, SN & $\begin{array}{l}\text { Que direito? Trajetórias e percepções dos usuários no } \\
\text { processo de acesso a medicamentos por mandados } \\
\text { judiciais em Santa Catarina }\end{array}$ & Original \\
\hline 72 & 2011 & POR & RS & Rosa, C & $\begin{array}{l}\text { Representações e intenção de uso de fitoterapia na } \\
\text { atenção básica à saúde }\end{array}$ & Tema Livre \\
\hline 73 & 2011 & ENG & RJ & Esher, A & $\begin{array}{l}\text { Logic models from an evaluability assessment of } \\
\text { pharmaceutical services for people living with HIV/ } \\
\text { AIDS }\end{array}$ & Tema Livre \\
\hline 74 & 2011 & POR & RS & Frohlich, SE & $\begin{array}{l}\text { Os indicadores de qualidade da prescrição de } \\
\text { medicamentos da Organização Mundial da Saúde } \\
\text { ainda são válidos? }\end{array}$ & Tema Livre \\
\hline 75 & 2011 & POR & MG & Saturnino, LTM & $\begin{array}{l}\text { O Internato Rural na formação do profissional } \\
\text { farmacêutico para a atuação no Sistema Único de } \\
\text { Saúde }\end{array}$ & Tema Livre \\
\hline 76 & 2011 & POR & RS & Brum, LFS & $\begin{array}{l}\text { Utilização de medicamentos por gestantes usuárias } \\
\text { do Sistema Único de Saúde no município de Santa } \\
\text { Rosa (RS, Brasil) }\end{array}$ & Temático \\
\hline 77 & 2011 & POR & MG & Gomes, PD & $\begin{array}{l}\text { Contracepção hormonal: uma comparação entre } \\
\text { pacientes das redes pública e privada de saúde }\end{array}$ & Temático \\
\hline 78 & 2011 & POR & MG & Melo, CM & $\begin{array}{l}\text { O uso de inibidores de apetite por mulheres: um } \\
\text { olhar a partir da perspectiva de gênero }\end{array}$ & Temático \\
\hline 79 & 2011 & POR & RJ & Paula, PAB & $\begin{array}{l}\text { O uso do medicamento na percepção do usuário do } \\
\text { Programa Hiperdia }\end{array}$ & Tema Livre \\
\hline 80 & 2011 & SPN & ESP & Iñesta, A & $\begin{array}{l}\text { La indústria farmacéutica y la sostenibilidad de los } \\
\text { sistemas de salud en países desarrollados y América } \\
\text { Latina }\end{array}$ & Temático \\
\hline 81 & 2011 & POR & RJ & $\begin{array}{l}\text { Santos-Pinto, } \\
\text { CDB }\end{array}$ & $\begin{array}{l}\text { Quem acessa o Programa Farmácia Popular do } \\
\text { Brasil? Aspectos do fornecimento público de } \\
\text { medicamentos }\end{array}$ & Tema Livre \\
\hline 82 & 2011 & POR & DF & Medeiros, EFF & $\begin{array}{l}\text { Intervenção interdisciplinar enquanto estratégia para } \\
\text { o Uso Racional de Medicamentos em idosos. }\end{array}$ & Temático \\
\hline 83 & 2011 & POR & SC & Oenning, D & $\begin{array}{l}\text { Conhecimento dos pacientes sobre os medicamentos } \\
\text { prescritos após consulta médica e dispensação }\end{array}$ & Tema Livre \\
\hline 84 & 2011 & POR & $\mathrm{RJ}$ & Rocha, DR & $\begin{array}{l}\text { Transgênicos - Plantas Produtoras de Fármacos } \\
\text { (PPF) }\end{array}$ & Tema Livre \\
\hline 85 & 2011 & POR & BA & Bastos, AA & $\begin{array}{l}\text { Fatores facilitadores e dificuldades no exercício da } \\
\text { vigilância sanitária de farmácias em Salvador-Bahia }\end{array}$ & Tema Livre \\
\hline
\end{tabular}


Quadro 1. Relação dos artigos selecionados para análise do campo teórico-prático da Assistência Farmacêutica nas páginas da Revista Ciência \& Saúde Coletiva, 1996-2019. RC\&SC, 2020.

\begin{tabular}{|c|c|c|c|c|c|c|}
\hline $\begin{array}{l}\text { Quan- } \\
\text { tidade }\end{array}$ & Ano & Idioma & $\begin{array}{l}\text { Local } \\
\text { (Estado } \\
\text { ou país) }\end{array}$ & $1^{\circ}$ autor & Título & $\begin{array}{l}\text { Sessão da } \\
\text { publicação }\end{array}$ \\
\hline 86 & 2011 & POR & MG & Daniela, A & $\begin{array}{l}\text { Dispensação farmacêutica: proposta de um modelo } \\
\text { para a prática }\end{array}$ & Tema Livre \\
\hline 87 & 2011 & POR & PB & Sá, LD & $\begin{array}{l}\text { Implantação da estratégia DOTS no controle da } \\
\text { Tuberculose na Paraíba: entre o compromisso } \\
\text { político e o envolvimento das equipes do programa } \\
\text { saúde da família (1999-2004) }\end{array}$ & Tema Livre \\
\hline 88 & 2011 & POR & BA & Alencar, TOS & $\begin{array}{l}\text { Assistência Farmacêutica no Programa Saúde da } \\
\text { Família: encontros e desencontros do processo de } \\
\text { organização }\end{array}$ & Tema Livre \\
\hline 89 & 2011 & POR & $\mathrm{RN}$ & Araújo, РTB & $\begin{array}{l}\text { Avaliação da qualidade da prescrição de } \\
\text { medicamentos de um hospital de ensino }\end{array}$ & Tema Livre \\
\hline 90 & 2011 & POR & RJ & Santana, RAL & $\begin{array}{l}\text { Sistema nacional de informações tóxico- } \\
\text { farmacológicas: o desafio da padronização dos } \\
\text { dados. }\end{array}$ & Tema Livre \\
\hline 91 & 2011 & POR & RS & Costa, SM & $\begin{array}{l}\text { Conhecimento dos clientes com tuberculose } \\
\text { pulmonar e seus familiares sobre adesão ao } \\
\text { tratamento e fatores associados, no município do } \\
\text { Rio Grande (RS). }\end{array}$ & Tema Livre \\
\hline 92 & 2011 & POR & RJ & $\begin{array}{l}\text { Osorio-de-Castro, } \\
\text { CGS }\end{array}$ & $\begin{array}{l}\text { Conhecimentos, práticas e percepções de } \\
\text { profissionais de saúde sobre o tratamento de malária } \\
\text { não complicada em municípios de alto risco da } \\
\text { Amazônia Legal. }\end{array}$ & Tema Livre \\
\hline 93 & 2011 & POR & PR & Vosgerau, MZS & $\begin{array}{l}\text { Consumo de medicamentos entre adultos na área de } \\
\text { abrangência de uma Unidade de Saúde da Família. }\end{array}$ & Tema Livre \\
\hline 94 & 2011 & POR & $\mathrm{CE}$ & Silva, IM & $\begin{array}{l}\text { Automedicação na adolescência: um desafio para a } \\
\text { educação em saúde }\end{array}$ & Tema Livre \\
\hline 95 & 2012 & POR & DF & Mota, DM & $\begin{array}{l}\text { Perfil da mortalidade por intoxicação com } \\
\text { medicamentos no Brasil, 1996-2005: retrato de uma } \\
\text { década }\end{array}$ & Temático \\
\hline 96 & 2012 & POR & SC & Blatt, CR & $\begin{array}{l}\text { Conhecimento popular e utilização dos } \\
\text { medicamentos genéricos na população do município } \\
\text { de Tubarão, SC }\end{array}$ & Temático \\
\hline 97 & 2012 & POR & MG & Firmino, KF & $\begin{array}{l}\text { Utilização de benzodiazepínicos no Serviço } \\
\text { Municipal de Saúde de Coronel Fabriciano, Minas } \\
\text { Gerais }\end{array}$ & Temático \\
\hline 98 & 2012 & POR & RJ & Esher, A & $\begin{array}{l}\text { Construindo Critérios de Julgamento em Avaliação: } \\
\text { especialistas e satisfação dos usuários com a } \\
\text { dispensação do tratamento do HIV/Aids }\end{array}$ & Temático \\
\hline 99 & 2012 & ENG/POR & RS & Rohden, F & $\begin{array}{l}\text { Capturados pelo sexo: a medicalização da } \\
\text { sexualidade masculina em dois momentos }\end{array}$ & Temático \\
\hline 100 & 2012 & POR & PR & Bruning, MCR & $\begin{array}{l}\text { A utilização da fitoterapia e de plantas medicinais } \\
\text { em unidades básicas de saúde nos municípios de } \\
\text { Cascavel e Foz do Iguaçu - Paraná: a visão dos } \\
\text { profissionais de saúde }\end{array}$ & Opinião \\
\hline 101 & 2012 & POR & RS & Junior, DS & $\begin{array}{l}\text { Judicialização do acesso ao tratamento de doenças } \\
\text { genéticas raras: a doença de Fabry no Rio Grande do } \\
\text { Sul. }\end{array}$ & Tema Livre \\
\hline 102 & 2012 & POR & RS & Guerin, GD & $\begin{array}{l}\text { Itinerários terapêuticos de usuários de } \\
\text { medicamentos de uma unidade de Estratégia de } \\
\text { Saúde da Família }\end{array}$ & Tema Livre \\
\hline
\end{tabular}


Quadro 1. Relação dos artigos selecionados para análise do campo teórico-prático da Assistência Farmacêutica nas páginas da Revista Ciência \& Saúde Coletiva, 1996-2019. RC\&SC, 2020.

\begin{tabular}{|c|c|c|c|c|c|c|}
\hline $\begin{array}{l}\text { Quan- } \\
\text { tidade }\end{array}$ & Ano & Idioma & $\begin{array}{c}\text { Local } \\
\text { (Estado } \\
\text { ou país) }\end{array}$ & $1^{\circ}$ autor & Título & $\begin{array}{l}\text { Sessão da } \\
\text { publicação }\end{array}$ \\
\hline 103 & 2012 & POR & SC & Galato, D & $\begin{array}{l}\text { Automedicação em estudantes universitários: a } \\
\text { influência da área de formação }\end{array}$ & Tema Livre \\
\hline 104 & 2012 & POR & MG & Martins, ELM & $\begin{array}{l}\text { Dispensações de psicotrópicos anorexígenos no } \\
\text { município de Juiz de Fora, Minas Gerais, Brasil }\end{array}$ & Tema Livre \\
\hline 105 & 2012 & POR & RS & Bianchin, MD & $\begin{array}{l}\text { Avaliação da qualidade de comprimidos de } \\
\text { propranolol e enalapril distribuídos no sistema } \\
\text { público de saúde em uma cidade do sul do Brasil. }\end{array}$ & Tema Livre \\
\hline 106 & 2012 & POR & MG & Luz, TCB & $\begin{array}{l}\text { Consumo de medicamentos por trabalhadores de } \\
\text { hospital }\end{array}$ & Tema Livre \\
\hline 107 & 2012 & POR & SC & Alano, GM & $\begin{array}{l}\text { Indicadores do Serviço de Atenção Farmacêutica } \\
\text { (SAF) da Universidade do Sul de Santa Catarina }\end{array}$ & Tema Livre \\
\hline 108 & 2012 & SPN & ARG & Colautti, MA & $\begin{array}{l}\text { Las personas que vivencon VIH/SIDA y su vínculo } \\
\text { com los antirretrovirales provistos por el Programa } \\
\text { Nacional en Argentina }\end{array}$ & Temático \\
\hline 109 & 2012 & POR & SC & Dandolini, BW & $\begin{array}{l}\text { Uso racional de antibióticos: uma experiência para } \\
\text { educação em saúde com escolares }\end{array}$ & Tema Livre \\
\hline 110 & 2012 & POR & RJ & Corrêa, MCDV & $\begin{array}{l}\text { Aborto e misoprostol: usos médicos, práticas de } \\
\text { saúde e controvérsia científica }\end{array}$ & Temático \\
\hline 111 & 2012 & POR & DF & Diniz, D & $\begin{array}{l}\text { Cytotec e aborto: a polícia, os vendedores e as } \\
\text { mulheres }\end{array}$ & Temático \\
\hline 112 & 2012 & POR & PI & Carvalho, ALM & $\begin{array}{l}\text { Adesão ao tratamento medicamentoso em usuários } \\
\text { cadastrados no Programa Hiperdia no município de } \\
\text { Teresina (PI) }\end{array}$ & Tema Livre \\
\hline 113 & 2012 & POR & RJ & $\begin{array}{l}\text { Lima-Dellamora, } \\
\text { EC }\end{array}$ & $\begin{array}{l}\text { Dispensação de medicamentos do componente } \\
\text { especializado em polos no Estado do Rio de Janeiro }\end{array}$ & Tema Livre \\
\hline 114 & 2012 & POR & SC & Alano, GM & $\begin{array}{l}\text { Conhecimento, consumo e acesso à contracepção de } \\
\text { emergência entre mulheres universitárias no sul do } \\
\text { Estado de Santa Catarina }\end{array}$ & Tema Livre \\
\hline 115 & 2012 & POR & RJ & Brito, MA & $\begin{array}{l}\text { Medicalização da Vida: Ética, Saúde Pública e } \\
\text { Indústria Farmacêutica }\end{array}$ & Resenha \\
\hline 116 & 2013 & POR & SP & Campos, RTO & $\begin{array}{l}\text { A Gestão Autônoma da Medicação: uma intervenção } \\
\text { analisadora de serviços em saúde mental }\end{array}$ & Temático \\
\hline 117 & 2013 & POR & GO & Braoios, A & $\begin{array}{l}\text { Uso de antimicrobianos pela população da cidade de } \\
\text { Jataí - GO, Brasil }\end{array}$ & Tema Livre \\
\hline 118 & 2013 & ENG & PR & Guidoni, CM & $\begin{array}{l}\text { Analysis of treatment of comorbidities and the } \\
\text { profile of medical consultations for diabetes mellitus }\end{array}$ & Tema Livre \\
\hline 119 & 2013 & POR & RJ & Corrêa, AD & $\begin{array}{l}\text { Uma Abordagem sobre o Uso de Medicamentos nos } \\
\text { Livros Didáticos de Biologia como Estratégia de } \\
\text { Promoção de Saúde }\end{array}$ & Tema Livre \\
\hline 120 & 2013 & POR & MG & Sousa, CV & $\begin{array}{l}\text { Análise da decisão de compra de medicamentos } \\
\text { frente a existência de produtos substitutos: um } \\
\text { estudo no município de Belo Horizonte }\end{array}$ & Tema Livre \\
\hline 121 & 2013 & ENG & RJ & Paumgartten, FJR & $\begin{array}{l}\text { Clinical use and control on thalidomide dispensing } \\
\text { in Brasilia-DF, Brazil, from } 2001 \text { to } 2012\end{array}$ & Tema Livre \\
\hline 122 & 2013 & POR & RS & Rocha BS & $\begin{array}{l}\text { Psicofármacos na Estratégia Saúde da Família: perfil } \\
\text { de utilização, acesso e estratégias para a promoção } \\
\text { do uso racional }\end{array}$ & Tema Livre \\
\hline 123 & 2013 & POR & RJ & Silva, MJS & $\begin{array}{l}\text { Avaliação dos serviços de farmácia dos hospitais } \\
\text { estaduais do Rio de Janeiro }\end{array}$ & Tema Livre \\
\hline
\end{tabular}


Quadro 1. Relação dos artigos selecionados para análise do campo teórico-prático da Assistência Farmacêutica nas páginas da Revista Ciência \& Saúde Coletiva, 1996-2019. RC\&SC, 2020.

\begin{tabular}{|c|c|c|c|c|c|c|}
\hline $\begin{array}{l}\text { Quan- } \\
\text { tidade }\end{array}$ & Ano & Idioma & $\begin{array}{c}\text { Local } \\
\text { (Estado } \\
\text { ou país) }\end{array}$ & $1^{\circ}$ autor & Título & $\begin{array}{l}\text { Sessão da } \\
\text { publicação }\end{array}$ \\
\hline 124 & 2013 & POR & RS & Moraes, CG & $\begin{array}{l}\text { Utilização de medicamentos entre crianças de zero } \\
\text { a seis anos: um estudo de base populacional no sul } \\
\text { do Brasil }\end{array}$ & Tema Livre \\
\hline 125 & 2013 & POR & SP & Ferreira, TR & $\begin{array}{l}\text { Analgésicos, antipiréticos e anti-inflamatórios não } \\
\text { esteroidais em prescrições pediátricas }\end{array}$ & Tema Livre \\
\hline 126 & 2013 & ENG & MG & Luz, TCB & $\begin{array}{l}\text { Social capital and under-utilization of medication } \\
\text { for financial reasons among elderly women: evidence } \\
\text { from two Brazilian health surveys }\end{array}$ & Tema Livre \\
\hline 127 & 2013 & POR & $\begin{array}{l}\text { ESP e } \\
\text { BRA }\end{array}$ & Rubio, JS & $\begin{array}{l}\text { Adaptação intercultural para português europeu do } \\
\text { questionário “Conocimiento del Paciente sobre sus } \\
\text { Medicamentos" (CPM-ES-ES) }\end{array}$ & Tema Livre \\
\hline 128 & 2013 & POR & SC & Cruzeta, APS & $\begin{array}{l}\text { Fatores associados à compreensão da prescrição } \\
\text { médica no Sistema Único de Saúde de um município } \\
\text { do Sul do Brasil }\end{array}$ & Tema Livre \\
\hline 129 & 2013 & POR & RN & Batista, AM & $\begin{array}{l}\text { Avaliação da propaganda de medicamentos veiculada } \\
\text { em emissoras de rádio }\end{array}$ & Tema Livre \\
\hline 130 & 2013 & POR & RJ & Itaborahy, C & O metifenidato no Brasil: uma década de publicações & Tema Livre \\
\hline 131 & 2013 & POR & $\mathrm{RJ}$ & Nobre, PFS & $\begin{array}{l}\text { Prescrição Off-Label no Brasil e nos EUA: aspectos } \\
\text { legais e paradoxos }\end{array}$ & Tema Livre \\
\hline 132 & 2013 & POR & SP & Marchi, KC & $\begin{array}{l}\text { Adesão à medicação em pacientes com doença de } \\
\text { Parkinson atendidos em ambulatório especializado }\end{array}$ & Tema Livre \\
\hline 133 & 2013 & POR & RJ & Falqueto, E & $\begin{array}{l}\text { Diretrizes para um Programa de Recolhimento de } \\
\text { Medicamentos Vencidos no Brasil }\end{array}$ & Tema Livre \\
\hline 134 & 2013 & POR & DF & Oliveira, MPF & $\begin{array}{l}\text { Perfil socioeconômico, epidemiológico e } \\
\text { farmacoterapêutico de idosos institucionalizados de } \\
\text { Brasília, Brasil }\end{array}$ & Tema Livre \\
\hline 135 & 2013 & POR & DF & Medeiros, M & $\begin{array}{l}\text { A tese da judicialização da saúde pelas elites: os } \\
\text { medicamentos para mucopolissacaridose }\end{array}$ & Tema Livre \\
\hline 136 & 2013 & POR & SP & Souza, ARL & $\begin{array}{l}\text { Contextos e padrões do uso indevido de } \\
\text { benzodiazepínicos entre mulheres }\end{array}$ & Tema Livre \\
\hline 137 & 2013 & POR & SP & Takitane, J & $\begin{array}{l}\text { Uso de anfetaminas por motoristas de caminhão } \\
\text { em rodovias do Estado de São Paulo: um risco à } \\
\text { ocorrência de acidentes de trânsito? }\end{array}$ & Temático \\
\hline 138 & 2013 & POR & PR & Girotto, E & $\begin{array}{l}\text { Adesão ao tratamento farmacológico e não } \\
\text { farmacológico e fatores associados na atenção } \\
\text { primária da hipertensão arterial }\end{array}$ & Tema Livre \\
\hline 139 & 2013 & POR & RS & Motter, FR & $\begin{array}{l}\text { Conhecimento sobre a farmacoterapia em } \\
\text { portadores de Hipertensão Arterial Sistêmica } \\
\text { usuários da Farmácia Básica de uma cidade no Sul } \\
\text { do Brasil }\end{array}$ & Tema Livre \\
\hline 140 & 2013 & POR & PI & Fontenele, RP & $\begin{array}{l}\text { A fitoterapia na Atenção Básica: olhares dos gestores } \\
\text { e profissionais da estratégia saúde da família de } \\
\text { Teresina - Piauí. }\end{array}$ & Tema Livre \\
\hline 141 & 2013 & SPN & ARG & Alonso, JP & $\begin{array}{l}\text { Cuidados paliativos: entre la humanización y la } \\
\text { medicalización del final de la vida }\end{array}$ & Tema Livre \\
\hline 142 & 2014 & POR & $\mathrm{BA}$ & Leão, DFL & $\begin{array}{l}\text { Avaliação de interações medicamentosas potenciais } \\
\text { em prescrições da atenção primária de Vitória da } \\
\text { Conquista-BA }\end{array}$ & Tema Livre \\
\hline 143 & 2014 & ENG & SP & Francisco, PMSB & $\begin{array}{l}\text { The use of medication and associated factors } \\
\text { among adults living in Campinas, São Paulo, Brazil: } \\
\text { differences between men and women }\end{array}$ & Tema Livre \\
\hline
\end{tabular}


Quadro 1. Relação dos artigos selecionados para análise do campo teórico-prático da Assistência Farmacêutica nas páginas da Revista Ciência \& Saúde Coletiva, 1996-2019. RC\&SC, 2020.

\begin{tabular}{|c|c|c|c|c|c|c|}
\hline $\begin{array}{l}\text { Quan- } \\
\text { tidade }\end{array}$ & Ano & Idioma & $\begin{array}{c}\text { Local } \\
\text { (Estado } \\
\text { ou país) }\end{array}$ & $1^{\circ}$ autor & Título & $\begin{array}{l}\text { Sessão da } \\
\text { publicação }\end{array}$ \\
\hline 144 & 2014 & POR & RJ & Lima, MAFD & $\begin{array}{l}\text { Contradições das políticas públicas voltadas } \\
\text { para doenças raras: o exemplo do programa de } \\
\text { tratamento da Osteogenese Imperfeita no SUS. }\end{array}$ & Opinião \\
\hline 145 & 2014 & POR & RJ & Pádula, M & $\begin{array}{l}\text { Atenção Farmacêutica e Atenção Flutuante: } \\
\text { formações de compromisso entre Farmácia e } \\
\text { Psicanálise }\end{array}$ & Tema Livre \\
\hline 146 & 2014 & SPN & $\begin{array}{l}\text { ESP e } \\
\text { BRA }\end{array}$ & Rubio, JS & $\begin{array}{l}\text { Validación del cuestionario de medida del } \\
\text { conocimiento del paciente sobre su medicamento } \\
\text { adaptado al portugués. }\end{array}$ & Tema Livre \\
\hline 147 & 2014 & POR & PR & Takahama, $\mathrm{CH}$ & $\begin{array}{l}\text { Perfil das exposições a medicamentos por mulheres } \\
\text { em idade reprodutiva atendidas por um Centro de } \\
\text { Informações toxicológicas. }\end{array}$ & Tema Livre \\
\hline 148 & 2014 & POR & RS & Mota, DM & $\begin{array}{l}\text { Há irracionalidades no consumo de inibidores de } \\
\text { apetite no Brasil? Uma análise farmacoeconométrica } \\
\text { de dados em painel }\end{array}$ & Tema Livre \\
\hline 149 & 2014 & POR & RJ & Mendes, LVP & $\begin{array}{l}\text { Uso Racional de Medicamentos entre indivíduos } \\
\text { com Diabetes Mellitus e Hipertensão Arterial no } \\
\text { Município do Rio de Janeiro, Brasil. }\end{array}$ & Tema Livre \\
\hline 150 & 2014 & POR & SP & Ribeiro, AG & $\begin{array}{l}\text { Antidepressivos: uso, adesão e conhecimento entre } \\
\text { estudantes de medicina }\end{array}$ & Tema Livre \\
\hline 151 & 2014 & POR & PE & Procopio, EVP & $\begin{array}{l}\text { Representação social da violência sexual e sua relação } \\
\text { com a adesão ao protocolo de quimioprofilaxia do } \\
\text { HIV em mulheres jovens e adolescentes }\end{array}$ & Tema Livre \\
\hline 152 & 2014 & POR & RJ & Batista, AJS & $\begin{array}{l}\text { Os Desafios da Nanotecnologia para a Vigilância } \\
\text { Sanitária de Medicamentos }\end{array}$ & Tema Livre \\
\hline 153 & 2014 & POR & BA & Silva, TO & $\begin{array}{l}\text { Descarte de medicamentos: Uma análise da prática } \\
\text { no programa saúde da família }\end{array}$ & Tema Livre \\
\hline 154 & 2014 & POR & PA & Cuentro, VS & $\begin{array}{l}\text { Prescrições medicamentosas de pacientes atendidos } \\
\text { no ambulatório de geriatria de um hospital } \\
\text { universitário: Estudo transversal descritivo }\end{array}$ & Original \\
\hline 155 & 2014 & POR & RJ & Souza, PP & $\begin{array}{l}\text { Preparação da assistência farmacêutica para } \\
\text { desastres: um estudo em cinco municípios brasileiros }\end{array}$ & Temático \\
\hline 156 & 2014 & POR & RJ & $\begin{array}{l}\text { Magarinos-Torres, } \\
\mathrm{R}\end{array}$ & $\begin{array}{l}\text { Medicamentos essenciais e processo de seleção em } \\
\text { práticas de gestão da Assistência Farmacêutica em } \\
\text { estados e municípios brasileiros }\end{array}$ & Tema Livre \\
\hline 157 & 2015 & $\begin{array}{l}\text { ENG/ } \\
\text { SPN/POR }\end{array}$ & $\begin{array}{l}\text { ESP/ } \\
\text { POR }\end{array}$ & Rubio, JS & $\begin{array}{l}\text { Medida del conocimiento del paciente sobre su } \\
\text { medicamento em farmácia comunitária en Portugal }\end{array}$ & Tema Livre \\
\hline 158 & 2015 & ENG/POR & RJ & Silva, RM & $\begin{array}{l}\text { Programa "Farmácia Popular do Brasil”: } \\
\text { caracterização e evolução entre 2004-2012 }\end{array}$ & Original \\
\hline 159 & 2015 & POR & $\mathrm{DF}$ & Soares, K & $\begin{array}{l}\text { Bioequivalência de medicamentos tópicos } \\
\text { dermatológicos: o cenário brasileiro e os desafios } \\
\text { para a vigilância sanitária }\end{array}$ & Tema Livre \\
\hline 160 & 2015 & ENG & MG & Vicente, ART & $\begin{array}{l}\text { Antidepressant use and associated factors among the } \\
\text { elderly: the Bambuí Project }\end{array}$ & Original \\
\hline 161 & 2015 & POR & RJ & Costa, RDF & $\begin{array}{l}\text { Aquisição de medicamentos para a Doença de } \\
\text { Alzheimer no Brasil: uma análise no sistema federal } \\
\text { de compras, } 2008 \text { a } 2013\end{array}$ & Original \\
\hline 162 & 2015 & ENG/POR & MG & Botelho, SF & $\begin{array}{l}\text { Planos de minimização de riscos em } \\
\text { farmacovigilância: uma ação de saúde pública para } \\
\text { promoção da segurança de medicamentos }\end{array}$ & Tema Livre \\
\hline
\end{tabular}


Quadro 1. Relação dos artigos selecionados para análise do campo teórico-prático da Assistência Farmacêutica nas páginas da Revista Ciência \& Saúde Coletiva, 1996-2019. RC\&SC, 2020.

\begin{tabular}{|c|c|c|c|c|c|c|}
\hline $\begin{array}{l}\text { Quan- } \\
\text { tidade }\end{array}$ & Ano & Idioma & $\begin{array}{c}\text { Local } \\
\text { (Estado } \\
\text { ou país) }\end{array}$ & $1^{\circ}$ autor & Título & $\begin{array}{l}\text { Sessão da } \\
\text { publicação }\end{array}$ \\
\hline 163 & 2015 & POR & SP & Zanella, CG & $\begin{array}{l}\text { Atuação do farmacêutico na dispensação de } \\
\text { medicamentos em Centros de Atenção Psicossocial } \\
\text { Adulto no Município de São Paulo, SP }\end{array}$ & Original \\
\hline 164 & 2015 & ENG/POR & SP & Monteiro, $\mathrm{CN}$ & $\begin{array}{l}\text { Cobertura de serviços públicos de saúde para gastos } \\
\text { com medicamentos e vacinas na população com } \\
\text { diabetes mellitus }\end{array}$ & Tema Livre \\
\hline 165 & 2015 & ENG/POR & SP & Fonseca, E & $\begin{array}{l}\text { Federalismo, Complexo Econômico-Industrial da } \\
\text { Saúde e Assistência Farmacêutica de Alto custo no } \\
\text { Brasil }\end{array}$ & Tema Livre \\
\hline 166 & 2015 & ENG & RS & Trevisan, LM & $\begin{array}{l}\text { Access to treatment for phenylketonuria by judicial } \\
\text { means in Rio Grande do Sul, Brazil }\end{array}$ & Tema Livre \\
\hline 167 & 2015 & ENG/POR & GO & Costa, SHN & $\begin{array}{l}\text { Prevalência do uso de drogas psicotrópicas em } \\
\text { unidades da polícia militar }\end{array}$ & Tema Livre \\
\hline 168 & 2015 & ENG & POR & Pires, $\mathrm{C}$ & $\begin{array}{l}\text { Brand names of Portuguese medication: } \\
\text { understanding the importance of their linguistic } \\
\text { structure and regulatory issues }\end{array}$ & Tema Livre \\
\hline 169 & 2015 & POR & $\mathrm{CE}$ & Silva, CDC & Por uma filosofia do medicamento & Tema Livre \\
\hline 170 & 2016 & POR & $\mathrm{RN}$ & Azevedo, AJP & $\begin{array}{l}\text { Consumo de ansiolíticos benzodiazepínicos: uma } \\
\text { correlação entre dados do SNGPC e indicadores } \\
\text { sociodemográficos nas capitais brasileiras }\end{array}$ & Original \\
\hline 171 & 2016 & POR & DF & Alexandre, RF & $\begin{array}{l}\text { Componente Especializado da Assistência } \\
\text { Farmacêutica: pacto federativo para a garantia da } \\
\text { integralidade do tratamento medicamentoso no SUS }\end{array}$ & Carta \\
\hline 172 & 2016 & POR & SP & Naloto, DCC & $\begin{array}{l}\text { Prescrição de benzodiazepínicos para adultos e } \\
\text { idosos de um ambulatório de saúde mental }\end{array}$ & Tema Livre \\
\hline 173 & 2016 & POR & SC & Nakamura, CA & $\begin{array}{l}\text { A construção do processo de trabalho no Núcleo } \\
\text { de Apoio à Saúde da Família: a experiência dos } \\
\text { farmacêuticos em um município do sul do Brasil }\end{array}$ & Tema Livre \\
\hline 174 & 2016 & ENG/POR & RJ & Silva, RM & $\begin{array}{l}\text { Assistência farmacêutica no município do Rio de } \\
\text { Janeiro, Brasil: evolução em aspectos selecionados de } \\
2008 \text { a } 2014\end{array}$ & Original \\
\hline 175 & 2016 & ENG/POR & MG & Pinto, IVL & $\begin{array}{l}\text { Avaliação da compreensão da farmacoterapia entre } \\
\text { idosos atendidos na Atenção Primária à Saúde de } \\
\text { Belo Horizonte, MG, Brasil }\end{array}$ & Original \\
\hline 176 & 2016 & ENG/POR & SP & Prado, MAMB & $\begin{array}{l}\text { Diabetes em idosos: uso de medicamentos e risco de } \\
\text { interação medicamentosa }\end{array}$ & Original \\
\hline 177 & 2016 & ENG/POR & MG & Lopes, LM & $\begin{array}{l}\text { Utilização de medicamentos potencialmente } \\
\text { inapropriados por idosos em domicílio }\end{array}$ & Original \\
\hline 178 & 2016 & POR & PR & Petris, AJ & $\begin{array}{l}\text { Participação do setor público no fornecimento de } \\
\text { medicamentos para dislipidemias em estudo de base } \\
\text { populacional }\end{array}$ & Tema Livre \\
\hline 179 & 2016 & ENG/POR & PR & Girotto, E & $\begin{array}{l}\text { Uso contínuo de medicamentos e condições de } \\
\text { trabalho entre motoristas de caminhão }\end{array}$ & Original \\
\hline 180 & 2016 & POR & RS & Dresch, AP & $\begin{array}{l}\text { Conhecimento dos pacientes sobre medicamentos } \\
\text { prescritos por odontólogos no sul do Brasil }\end{array}$ & Tema Livre \\
\hline 181 & 2017 & ENG/POR & RJ & Pimentel, A & $\begin{array}{l}\text { A breve vida do Norplant }{ }^{\circledR} \text { no Brasil: controvérsias e } \\
\text { reagregações entre ciência, sociedade e Estado }\end{array}$ & Temático \\
\hline 182 & 2017 & ENG/POR & SP & Melo, DP & $\begin{array}{l}\text { A contribuição do farmacêutico para a promoção do } \\
\text { acesso e uso racional de medicamentos essenciais no } \\
\text { SUS }\end{array}$ & Tema Livre \\
\hline
\end{tabular}


Quadro 1. Relação dos artigos selecionados para análise do campo teórico-prático da Assistência Farmacêutica nas páginas da Revista Ciência \& Saúde Coletiva, 1996-2019. RC\&SC, 2020.

\begin{tabular}{|c|c|c|c|c|c|c|}
\hline $\begin{array}{l}\text { Quan- } \\
\text { tidade }\end{array}$ & Ano & Idioma & $\begin{array}{l}\text { Local } \\
\text { (Estado } \\
\text { ou país) }\end{array}$ & $1^{\circ}$ autor & Título & $\begin{array}{l}\text { Sessão da } \\
\text { publicação }\end{array}$ \\
\hline 183 & 2017 & ENG/POR & RJ & Bonan, C & $\begin{array}{l}\text { Absorção e metabolização dos hormônios sexuais e } \\
\text { sua transformação em tecnologias contraceptivas: } \\
\text { percursos do pensamento médico no Brasil }\end{array}$ & Temático \\
\hline 184 & 2017 & ENG/POR & MG & Garcia, MM & $\begin{array}{l}\text { Avaliação econômica dos Programas Rede Farmácia } \\
\text { de Minas do SUS versus Farmácia Popular do Brasil }\end{array}$ & Tema Livre \\
\hline 185 & 2017 & ENG/POR & SP & Melo, DO & $\begin{array}{l}\text { Capacitação e intervenções de técnicos de farmácia } \\
\text { na dispensação de medicamentos em Atenção } \\
\text { Primária à Saúde }\end{array}$ & Tema Livre \\
\hline 186 & 2017 & POR & SP & Yamauti, SM & $\begin{array}{l}\text { Essencialidade e racionalidade da relação nacional de } \\
\text { medicamentos essenciais do Brasil }\end{array}$ & Tema Livre \\
\hline 187 & 2017 & ENG/POR & DF & Araújo, SQ & $\begin{array}{l}\text { A organização dos serviços farmacêuticos no sistema } \\
\text { único de saúde em regiôes de saúde }\end{array}$ & Temático \\
\hline 188 & 2017 & ENG/POR & MG & Martins, MAP & $\begin{array}{l}\text { Adaptação Transcultural do Oral Anticoagulation } \\
\text { Knowledge Test para o Português do Brasil }\end{array}$ & Tema Livre \\
\hline 189 & 2017 & ENG/POR & SP & $\begin{array}{l}\text { Caccia-Bava, } \\
\text { MCGG }\end{array}$ & $\begin{array}{l}\text { Disponibilidade de medicamentos fitoterápicos e } \\
\text { plantas medicinais nas unidades de atenção básica } \\
\text { do Estado de São Paulo: resultados do Programa } \\
\text { Nacional de Melhoria do Acesso e da Qualidade da } \\
\text { Atenção Básica (PMAQ) }\end{array}$ & Tema Livre \\
\hline 190 & 2017 & ENG/POR & $\mathrm{DF}$ & Santana, RS & $\begin{array}{l}\text { Registro e incorporação de tecnologias no SUS: } \\
\text { barreiras de acesso a medicamentos para doenças da } \\
\text { pobreza? }\end{array}$ & Original \\
\hline 191 & 2017 & POR & MG & Silva, SN & $\begin{array}{l}\text { Assistência Farmacêutica na Saúde Mental: um } \\
\text { diagnóstico dos Centros de Atenção Psicossocial }\end{array}$ & Tema Livre \\
\hline 192 & 2017 & ENG/POR & $\mathrm{BA}$ & Lisboa, ES & $\begin{array}{l}\text { Por que as pessoas recorrem ao Judiciário para obter } \\
\text { o acesso aos medicamentos? O caso das insulinas } \\
\text { análogas na Bahia }\end{array}$ & Original \\
\hline 193 & 2017 & \begin{tabular}{l|l} 
ENG/ \\
POR/SPN
\end{tabular} & RJ & Luiza, VL & $\begin{array}{l}\text { Desafios de uma parceria para o desenvolvimento de } \\
\text { produtos: o caso de um tratamento para malária }\end{array}$ & Temático \\
\hline 194 & 2017 & \begin{tabular}{|l|} 
ENG/ \\
POR/SPN \\
\end{tabular} & SP & Fedatto, MS & $\begin{array}{l}\text { Epidemia da AIDS e a Sociedade Moçambicana de } \\
\text { Medicamentos: análise da cooperação brasileira }\end{array}$ & Temático \\
\hline 195 & 2017 & ENG & $\mathrm{RN}$ & Costa, VS & $\begin{array}{l}\text { Prescription medication by physiotherapists: a } \\
\text { Brazilian view of the United Kingdom, Canada, } \\
\text { Australia and New Zealand }\end{array}$ & Revisão \\
\hline 196 & 2017 & \begin{tabular}{l|} 
ENG/ \\
POR/SPN
\end{tabular} & SP & Lima, JHS & $\begin{array}{l}\text { Saúde global e política externa brasileira: } \\
\text { negociações referentes à inovação e propriedade } \\
\text { intelectual }\end{array}$ & Temático \\
\hline 197 & 2017 & ENG/POR & RJ & Hasenclever, L & $\begin{array}{l}\text { A indústria de fitoterápicos brasileira: desafios e } \\
\text { oportunidades }\end{array}$ & Original \\
\hline 198 & 2017 & ENG/POR & DF & Pontes, MA & $\begin{array}{l}\text { Aplicação de recursos financeiros para aquisição de } \\
\text { medicamentos para atenção básica em municípios } \\
\text { brasileiros }\end{array}$ & Original \\
\hline 199 & 2017 & ENG/POR & RJ & $\begin{array}{l}\text { Osorio-de-Castro, } \\
\text { CGS }\end{array}$ & $\begin{array}{l}\text { Assistência Farmacêutica: um campo em } \\
\text { consolidação }\end{array}$ & Editoral \\
\hline 200 & 2017 & ENG/POR & SC & Rover, MRM & $\begin{array}{l}\text { Avaliação da capacidade de gestão do componente } \\
\text { especializado da assistência farmacêutica }\end{array}$ & Original \\
\hline 201 & 2017 & ENG/POR & MG & Barbosa, MM & $\begin{array}{l}\text { Avaliação da infraestrutura da Assistência } \\
\text { Farmacêutica no Sistema Único de Saúde em Minas } \\
\text { Gerais }\end{array}$ & Original \\
\hline 202 & 2017 & ENG/POR & RJ & Chaves, GC & $\begin{array}{l}\text { Compras públicas de medicamentos para hepatite C } \\
\text { no Brasil no período de } 2005 \text { a } 2015\end{array}$ & Original \\
\hline
\end{tabular}


Quadro 1. Relação dos artigos selecionados para análise do campo teórico-prático da Assistência Farmacêutica nas páginas da Revista Ciência \& Saúde Coletiva, 1996-2019. RC\&SC, 2020.

\begin{tabular}{|c|c|c|c|c|c|c|}
\hline $\begin{array}{l}\text { Quan- } \\
\text { tidade }\end{array}$ & Ano & Idioma & $\begin{array}{l}\text { Local } \\
\text { (Estado } \\
\text { ou país) }\end{array}$ & $1^{\circ}$ autor & Título & $\begin{array}{l}\text { Sessão da } \\
\text { publicação }\end{array}$ \\
\hline 203 & 2017 & ENG & RJ & Bermudez, JZ & $\begin{array}{l}\text { Contemporary challenges on access to medicines: } \\
\text { beyond the UNSG High-Level Panel }\end{array}$ & Debate \\
\hline 204 & 2017 & SPN/POR & SP & Costa, KS & $\begin{array}{l}\text { Coordinación entre servicios farmacéuticos para una } \\
\text { farmacoterapia integrada: el caso de Cataluña }\end{array}$ & Original \\
\hline 205 & 2017 & ENG/POR & RJ & Vidal TJ & $\begin{array}{l}\text { Demandas judiciais por medicamentos } \\
\text { antineoplásicos: a ponta de um iceberg? }\end{array}$ & Original \\
\hline 206 & 2017 & ENG & $\mathrm{RJ}$ & Silva, RM & $\begin{array}{l}\text { Farmácia Popular Program: pharmaceutical Market } \\
\text { analysis of antihypertensive acting on the renin- } \\
\text { angiotensin system medicines }\end{array}$ & Original \\
\hline 207 & 2017 & ENG/POR & RS & Guttier, MC & $\begin{array}{l}\text { Impacto de intervenções para promoção do uso de } \\
\text { medicamentos genéricos: revisão sistemática }\end{array}$ & Temático \\
\hline 208 & 2017 & ENG/POR & RJ & Caetano, $\mathrm{R}$ & $\begin{array}{l}\text { Incorporação de novos medicamentos pela } \\
\text { Comissão Nacional de Incorporação de Tecnologias } \\
\text { do SUS, } 2012 \text { a junho de } 2016\end{array}$ & Original \\
\hline 209 & 2017 & ENG & RJ & Paumgartten, FJR & $\begin{array}{l}\text { Non bioequivalent prescription drug } \\
\text { interchangeability, concerns on patient safety and } \\
\text { drug market dynamics in Brazil }\end{array}$ & Original \\
\hline 210 & 2017 & ENG/POR & $\mathrm{RJ}$ & Mendoza-Ruiz, A & $\begin{array}{l}\text { Organización Panamericana de la Salud. Conceptos, } \\
\text { estrategias y herramientas para una política } \\
\text { farmacéutica nacional em las Américas. Washington, } \\
\text { DC: OPS, Unidad de Medicamentos y Tecnologías } \\
\text { Sanitarias }\end{array}$ & Resenha \\
\hline 211 & 2017 & ENG & MG & Luz, TCB & $\begin{array}{l}\text { Pharmaceutical Services in Primary Health Care: are } \\
\text { pharmacists and users on the same page? }\end{array}$ & Original \\
\hline 212 & 2017 & ENG/POR & $\mathrm{RJ}$ & $\begin{array}{l}\text { Vasconcelos, } \\
\text { DMM }\end{array}$ & $\begin{array}{l}\text { Política Nacional de Medicamentos em retrospectiva: } \\
\text { um balanço de (quase) } 20 \text { anos de implementação }\end{array}$ & Opinião \\
\hline 213 & 2017 & ENG/POR & $\mathrm{AM}$ & Gomes, VP & $\begin{array}{l}\text { Prevalência do consumo de medicamentos em } \\
\text { adultos brasileiros: uma revisão sistemática }\end{array}$ & Revisão \\
\hline 214 & 2017 & ENG & EUA & Abbott, FM & $\begin{array}{l}\text { Reflections on the Report of the UN Secretary } \\
\text { General's High Level Panelon Access to Medicines }\end{array}$ & Debate \\
\hline 215 & 2017 & ENG & $\mathrm{RJ}$ & Azeredo, TB & $\begin{array}{l}\text { Sustainability of ARV provision in developing } \\
\text { countries: challenging a framework based on program } \\
\text { history }\end{array}$ & Temático \\
\hline 216 & 2017 & ENG/POR & RJ & Esher, A & $\begin{array}{l}\text { Uso racional de medicamentos, farmaceuticalização } \\
\text { e usos do metilfenidato }\end{array}$ & Original \\
\hline 217 & 2017 & POR & SC & Zeni, ALB & $\begin{array}{l}\text { Utilização de plantas medicinais como remédio } \\
\text { caseiro na Atenção Primária em Blumenau-SC }\end{array}$ & Tema Livre \\
\hline 218 & 2017 & ENG/POR & SP & Oliveira, JFM & $\begin{array}{l}\text { Tendência da mortalidade por intoxicação } \\
\text { medicamentosa entre gêneros e faixas etárias no } \\
\text { Estado de São Paulo, 1996-2012 }\end{array}$ & Temático \\
\hline 219 & 2018 & ENG/POR & MG & Botelho, SF & $\begin{array}{l}\text { Análise de medicamentos novos registrados no Brasil } \\
\text { na perspectiva do Sistema Único de Saúde e da carga } \\
\text { de doença }\end{array}$ & Tema Livre \\
\hline 220 & 2018 & ENG & SP & Okumura, LM & $\begin{array}{l}\text { A Glance in Hepatitis C Policy in Brazil: Access and } \\
\text { Performance }\end{array}$ & Carta \\
\hline 221 & 2018 & POR & ES & Bonadiman, RL & $\begin{array}{l}\text { Nível de satisfação dos usuários e verificação do } \\
\text { conhecimento dos farmacêuticos em farmácias } \\
\text { públicas do Espírito Santo, Brasil }\end{array}$ & Tema Livre \\
\hline 222 & 2018 & ENG/POR & $\mathrm{PE}$ & Borba, AKOT & $\begin{array}{l}\text { Fatores associados à adesão terapêutica em idosos } \\
\text { diabéticos assistidos na atenção primária de saúde }\end{array}$ & Tema Livre \\
\hline
\end{tabular}


Quadro 1. Relação dos artigos selecionados para análise do campo teórico-prático da Assistência Farmacêutica nas páginas da Revista Ciência \& Saúde Coletiva, 1996-2019. RC\&SC, 2020.

\begin{tabular}{|c|c|c|c|c|c|c|}
\hline $\begin{array}{l}\text { Quan- } \\
\text { tidade }\end{array}$ & Ano & Idioma & $\begin{array}{c}\text { Local } \\
\text { (Estado } \\
\text { ou país) }\end{array}$ & $1^{\circ}$ autor & Título & $\begin{array}{l}\text { Sessão da } \\
\text { publicação }\end{array}$ \\
\hline 223 & 2018 & ENG & MG & Vicente, ART & $\begin{array}{l}\text { Religiousness, social support and the use of } \\
\text { antidepressants among the elderly: A population- } \\
\text { based study }\end{array}$ & Tema Livre \\
\hline 224 & 2018 & POR & MG & Silva, GD & $\begin{array}{l}\text { Perfil de gastos com o tratamento da Artrite } \\
\text { Reumatoide para pacientes do Sistema Único de } \\
\text { Saúde em Minas Gerais, Brasil, de } 2008 \text { a } 2013\end{array}$ & Tema Livre \\
\hline 225 & 20118 & POR & RS & Alves, SP & $\begin{array}{l}\text { O perfil dos cuidadores de pacientes pediátricos com } \\
\text { fibrose cística }\end{array}$ & Original \\
\hline 226 & 2018 & ENG & RS & Tramontina, MY & $\begin{array}{l}\text { Comorbidades, medicamentos potencialmente } \\
\text { perigosos e de baixo índice terapêutico: fatores } \\
\text { associados à busca da emergência hospitalar }\end{array}$ & Original \\
\hline 227 & 2018 & POR & $\mathrm{CE}$ & Costa, AC & $\begin{array}{l}\text { Satisfação dos pacientes com doença de Chagas } \\
\text { atendidos por um serviço de atenção farmacêutica } \\
\text { no estado do Ceará, Brasil }\end{array}$ & Temático \\
\hline 228 & 2018 & ENG/POR & RJ & Bermudez, JAZ & $\begin{array}{l}\text { Assistência Farmacêutica nos } 30 \text { anos do SUS na } \\
\text { perspectiva da integralidade }\end{array}$ & Temático \\
\hline 229 & 2018 & ENG/POR & ITA & Sachy, M & $\begin{array}{l}\text { Assistência Farmacêutica em Moçambique: a ajuda } \\
\text { externa na provisão pública de medicamentos }\end{array}$ & Temático \\
\hline 230 & 2018 & ENG/POR & RJ & Freitas, PS & $\begin{array}{l}\text { Uso de serviços de saúde e de medicamentos por } \\
\text { portadores de Hipertensão e Diabetes no Município } \\
\text { do Rio de Janeiro, Brasil }\end{array}$ & Tema Livre \\
\hline 231 & 2018 & ENG/POR & MG & Silva, MRR & $\begin{array}{l}\text { Uso de medicamentos e fatores associados à } \\
\text { polifarmácia em indivíduos com diabetes mellitus } \\
\text { em Minas Gerais, Brasil }\end{array}$ & Temático \\
\hline 232 & 2018 & ENG & MA & Lessa, CCR & $\begin{array}{l}\text { Prevalence and factors associated with surfactant } \\
\text { use in Brazilian Neonatal Intensive Care Units: A } \\
\text { multilevel analysis }\end{array}$ & Tema Livre \\
\hline 233 & 2018 & POR & RS & Mota, DM & $\begin{array}{l}\text { Recomendação de códigos da CID-10 para vigilância } \\
\text { de reações adversas e intoxicações a medicamentos }\end{array}$ & Tema Livre \\
\hline 234 & 2018 & POR & SC & Martinhago, F & $\begin{array}{l}\text { TDAH e Ritalina: neuronarrativas em uma } \\
\text { comunidade virtual da Rede Social Facebook }\end{array}$ & Temático \\
\hline 235 & 2018 & POR & RS & Mota, DM & $\begin{array}{l}\text { Análise da preferência digital de idade no sistema de } \\
\text { farmacovigilância do Brasil, 2008-2013 }\end{array}$ & Tema Livre \\
\hline 236 & 2018 & POR & RJ & Madruga, LGSL & $\begin{array}{l}\text { Aspectos relacionados à utilização de antirretrovirais } \\
\text { em pacientes de alta complexidade no estado do Rio } \\
\text { de Janeiro, Brasil }\end{array}$ & Tema Livre \\
\hline 237 & 2018 & POR & SC & Mattos, G & $\begin{array}{l}\text { Plantas medicinais e fitoterápicos na Atenção } \\
\text { Primária em Saúde: percepção dos profissionais }\end{array}$ & Tema Livre \\
\hline 238 & 2018 & ENG/POR & SP & Nagai, KL & $\begin{array}{l}\text { Uso de rastreadores para busca de reações adversas a } \\
\text { medicamentos como motivo de admissão de idosos } \\
\text { em pronto-socorro }\end{array}$ & Tema Livre \\
\hline 239 & 2018 & ENG/POR & SC & Leite, SN & $\begin{array}{l}\text { Ciência, Tecnologia e Assistência Farmacêutica } \\
\text { em pauta: contribuições da sociedade para a } 16^{\mathrm{a}} \\
\text { Conferência Nacional de Saúde }\end{array}$ & Opinião \\
\hline 240 & 2019 & ENG/POR & MG & Veloso, RCSG & $\begin{array}{l}\text { Fatores associados às interações medicamentosas em } \\
\text { idosos internados em hospital de alta complexidade }\end{array}$ & Original \\
\hline 241 & 2019 & POR & RS & Raminelli, M & Medicamentos na amamentação: quais as evidências? & Revisão \\
\hline 242 & 2019 & ENG & RJ & Silva, MJS & $\begin{array}{l}\text { Origin-destination flows in chemotherapy for breast } \\
\text { cancer in Brazil: implications for pharmaceutical } \\
\text { services }\end{array}$ & Tema Livre \\
\hline
\end{tabular}


Quadro 1. Relação dos artigos selecionados para análise do campo teórico-prático da Assistência Farmacêutica nas páginas da Revista Ciência \& Saúde Coletiva, 1996-2019. RC\&SC, 2020.

\begin{tabular}{|c|c|c|c|c|c|c|}
\hline $\begin{array}{l}\text { Quan- } \\
\text { tidade }\end{array}$ & Ano & Idioma & $\begin{array}{c}\text { Local } \\
\text { (Estado } \\
\text { ou país) }\end{array}$ & $1^{\circ}$ autor & Título & $\begin{array}{l}\text { Sessão da } \\
\text { publicação }\end{array}$ \\
\hline 243 & 2019 & POR & SC & Nascimento, DZ & $\begin{array}{l}\text { Alternativas para identificar interações } \\
\text { medicamentosas entre as reações adversas a } \\
\text { medicamentos em unidades hospitalares }\end{array}$ & Carta \\
\hline 244 & 2019 & POR & GO & Cardoso, BS & $\begin{array}{l}\text { O uso da fitoterapia durante a gestação: um } \\
\text { panorama global }\end{array}$ & Tema Livre \\
\hline 245 & 2019 & POR & RJ & Ribeiro, LHL & $\begin{array}{l}\text { Análise dos programas de plantas medicinais e } \\
\text { fitoterápicos no Sistema Único de Saúde (SUS) sob a } \\
\text { perspectiva territorial }\end{array}$ & Original \\
\hline 246 & 2019 & ENG & ESP/BRA & $\begin{array}{l}\text { Iniesta-Navalón, } \\
\text { C }\end{array}$ & $\begin{array}{l}\text { Potential and clinical relevant drug-drug interactions } \\
\text { among elderly from nursing homes: a multicentre } \\
\text { study in Murcia, Spain }\end{array}$ & Tema Livre \\
\hline 247 & 2019 & ENG/POR & RJ & Lima, SGG & $\begin{array}{l}\text { O processo de incorporação de tecnologias em saúde } \\
\text { no brasil em uma perspectiva internacional }\end{array}$ & Tema Livre \\
\hline 248 & 2019 & ENG & PR & Muller, EV & $\begin{array}{l}\text { Risk factors for cardiovascular disease in HIV/AIDS } \\
\text { patients treated with highly active antiretroviral } \\
\text { therapy (HAART) in the central-southern region of } \\
\text { the state of Paraná - Brazil }\end{array}$ & Tema Livre \\
\hline 249 & 2019 & ENG/POR & MG & Carvalho, PP & $\begin{array}{l}\text { Fatores associados à adesão à Terapia Antirretroviral } \\
\text { em adultos: revisão integrativa de literatura }\end{array}$ & Original \\
\hline 250 & 2019 & ENG/POR & RJ & Zorzanelli, RT & $\begin{array}{l}\text { Consumo do benzodiazepínico clonazepam } \\
\text { (Rivotril }^{\circledR} \text { ) no estado do Rio de Janeiro, Brasil, 2009- } \\
\text { 2013: estudo ecológico }\end{array}$ & Tema Livre \\
\hline 251 & 2019 & ENG/POR & $\mathrm{PE}$ & Barbosa, VFB & $\begin{array}{l}\text { Medicalização e Saúde Indígena: uma análise do } \\
\text { consumo de psicotrópicos pelos índios Xukuru de } \\
\text { Cimbres }\end{array}$ & Tema Livre \\
\hline 252 & 2019 & POR & RJ & Oliveira, NR & $\begin{array}{l}\text { Revisão dos dispositivos legais e normativos } \\
\text { internacionais e nacionais sobre gestão de } \\
\text { medicamentos e de seus resíduos }\end{array}$ & Tema Livre \\
\hline 253 & 2019 & ENG/POR & $\mathrm{CE}$ & Santos, VF & $\begin{array}{l}\text { Uso do telefone para adesão de pessoas vivendo com } \\
\text { hiv/aids à terapia antirretroviral: Revisão sistemática }\end{array}$ & Revisão \\
\hline 254 & 2019 & POR & SP & Didone, TVN & $\begin{array}{l}\text { Validação do questionário “Conocimiento del } \\
\text { Paciente sobre sus Medicamentos” (CPM-ES-ES) }\end{array}$ & Tema Livre \\
\hline 255 & 2019 & ENG & SP & Molino, CGRC & $\begin{array}{l}\text { Comparison of the methodological quality and } \\
\text { transparency of Brazilian practice guidelines }\end{array}$ & Tema Livre \\
\hline 256 & 2019 & ENG/POR & SP & Santimaria, MR & $\begin{array}{l}\text { Falha no diagnóstico e no tratamento } \\
\text { medicamentoso da hipertensão arterial em idosos } \\
\text { brasileiros - Estudo FIBRA }\end{array}$ & Tema Livre \\
\hline 257 & 2019 & ENG/POR & $\mathrm{DF}$ & Barberato, LC & $\begin{array}{l}\text { O farmacêutico na atenção primária no Brasil: uma } \\
\text { inserção em construção }\end{array}$ & Revisão \\
\hline 258 & 2019 & ENG & RJ & Paumgartten, FJR & $\begin{array}{l}\text { The tale of lenalidomide clinical superiority over } \\
\text { thalidomide and regulatory and cost-effectiveness } \\
\text { issues }\end{array}$ & Tema Livre \\
\hline 259 & 2019 & POR & RJ & Santos, JS & $\begin{array}{l}\text { Interações medicamentosas potenciais em adultos e } \\
\text { idosos na atenção primária }\end{array}$ & Tema Livre \\
\hline 260 & 2019 & POR & RJ & Ferreira, DP & $\begin{array}{l}\text { Adesão de adolescentes com fibrose cística a terapia } \\
\text { de reposição enzimática: fatores associados }\end{array}$ & Tema Livre \\
\hline
\end{tabular}

Nota: Idioma (ENG: Inglês, POR: Português, SPN: Espanhol. Abreviatura dos idiomas de acordo com a Associação Brasileira do ISBN). Fonte: Elaboração própria, 2020. 


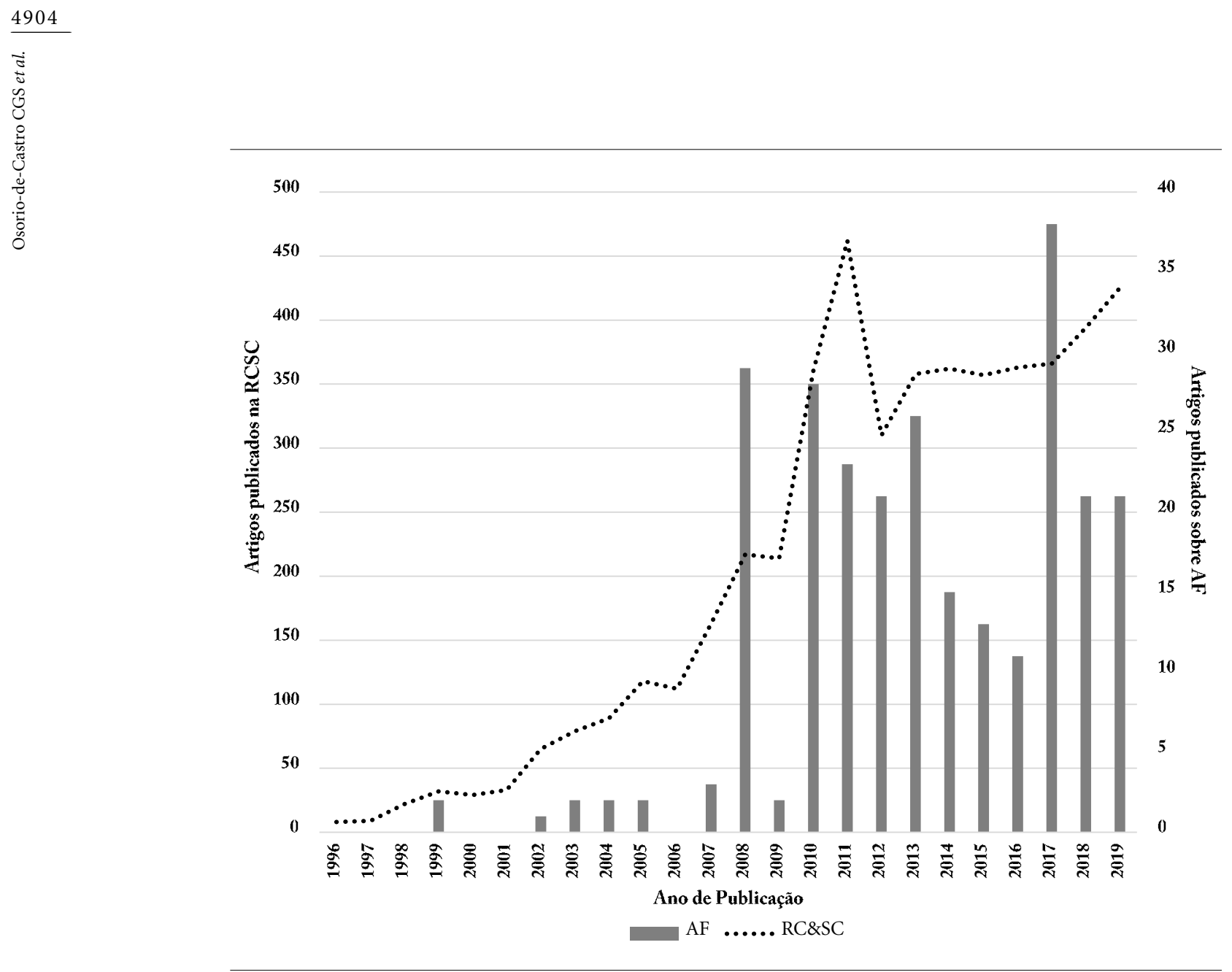

Figura 2. Número de artigos publicados na Revista Ciência \& Saúde Coletiva, de 1996 a 2019, com destaque para o campo teórico-prático da Assistência Farmacêutica. RC\&SC, 2020.

Nota: eixo da esquerda mostra número total de artigos publicados na RC\&SC e o da direita o número de artigos em Assistência Farmacêutica (AF), em números absolutos.

Fonte: Elaboração própria.

A gestão (B) concentra muitos artigos no tema secundários da política de medicamentos, mas ao longo dos períodos de observação muitos novos temas surgem, como provisão pública, compras públicas, avaliação de tecnologias, serviços de AF. O grande tema que inclui os aspectos tangenciais ao ciclo da AF (C) englobou em todos os períodos de observação temas secundários relacionados à regulação sanitária; no entanto, no último período, temas ligados à Saúde Global, registro, avaliação de tecnologias e pesquisa e desenvolvimento se estabeleceram.

Com a classificação dos artigos em temáticas principais, secundárias e especificidades, foi possível construir uma ontologia da AF nas páginas da RC\&SC, que está retratada no Quadro 2.
O quadro mostra para cada tema principal os temas secundários e especificidades dependentes, e sua frequência. Há duas características marcantes do quadro: a primeira é que temas secundários e especificidades estão presentes em diferentes temáticas principais, a depender da abordagem do trabalho. A segunda é que temas secundários também aparecem como especificidades - no caso em que são o objeto do trabalho. Nas especificidades, destaca-se que o objeto genérico "marcos e conceitos" diminui ao longo do tempo, enquanto que "idosos”, "psicofármacos” e "atenção primária em saúde" são especificidades que se estabelecem como relevantes nas publicações. Um destaque pode ser dado ao número de artigos de tema secundário classificado como 


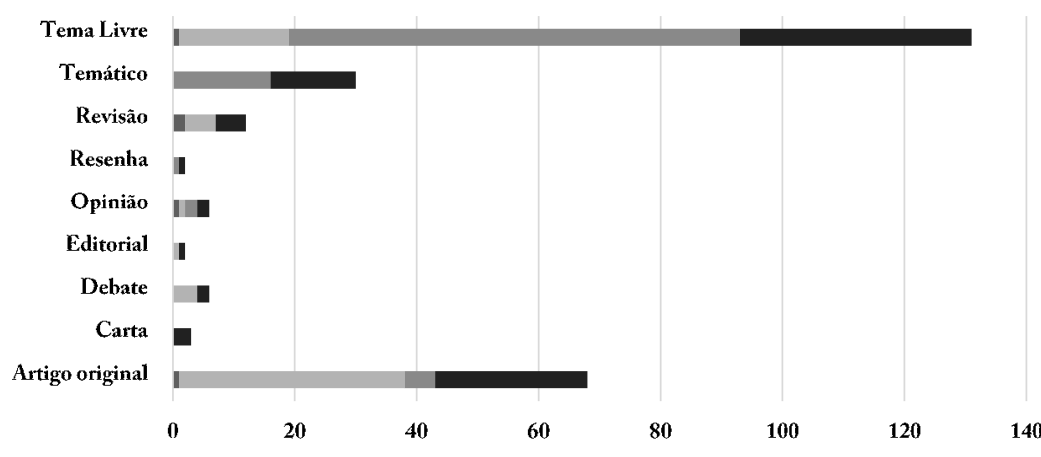

A $\square$ 1996-2003 $\square 2004-2010 \square 2011-2015 \square 2016-2019$
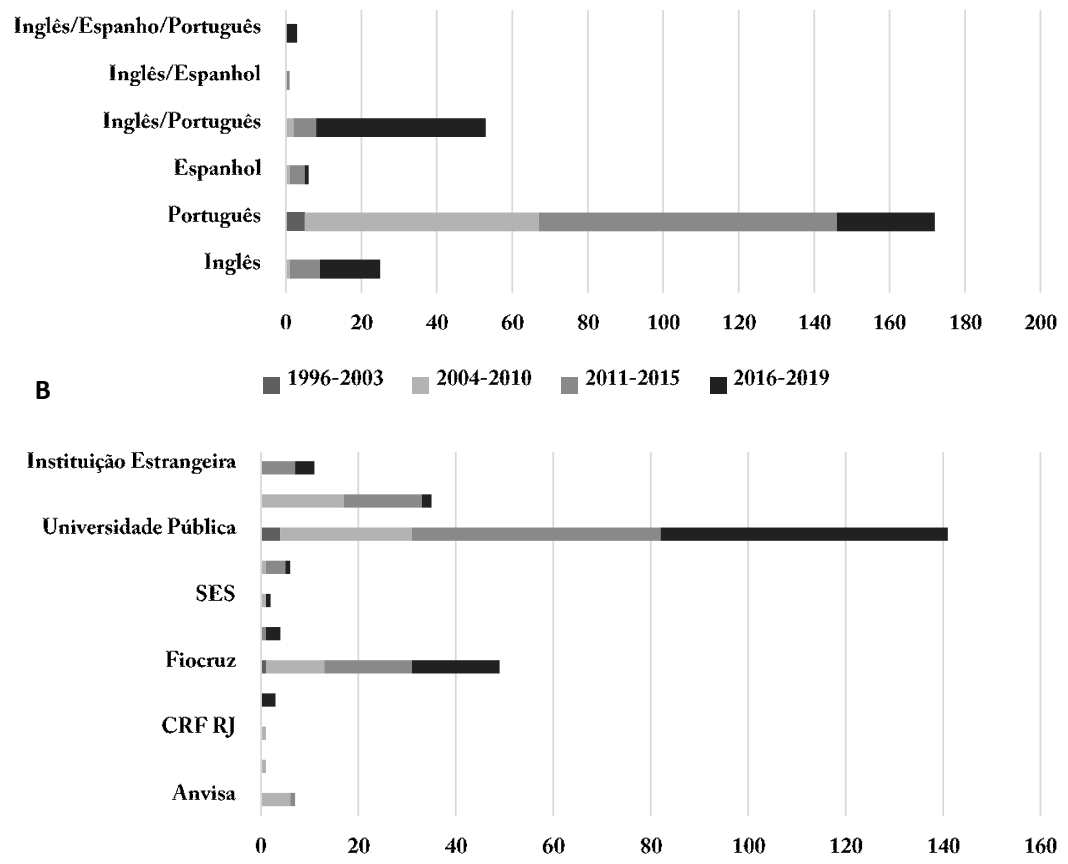

$\mathrm{C}$

$\square$ 1996-2003 2004-2010 $\square$ 2011-2015 2016-2019

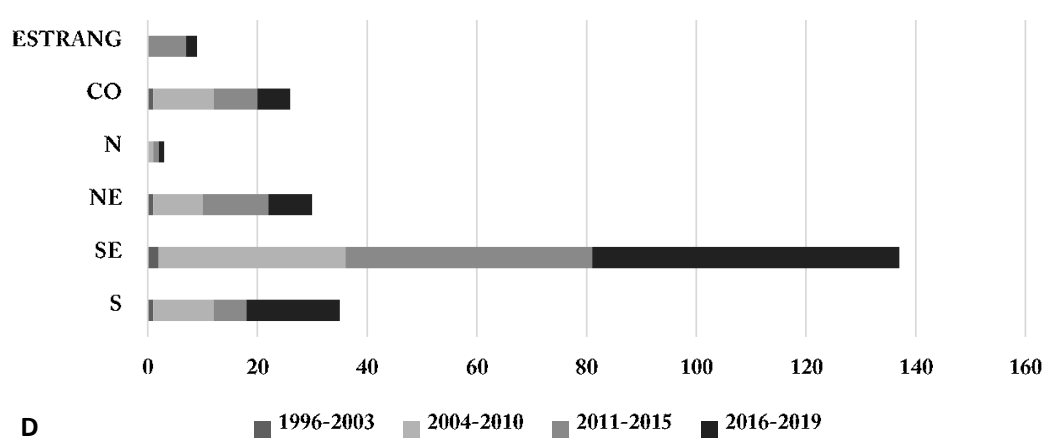

Figura 3. Características de artigos publicados na Revista Ciência \& Saúde Coletiva, de 1996 a 2019, no campo teórico-prático da Assistência Farmacêutica, quanto a (A) tipo de artigo, (B) idioma de publicação, (C) tipo de instituição de origem do primeiro autor e (D) local de origem do primeiro autor. RC\&SC, 2020.

Nota: O local de origem do primeiro autor foi classificado por regiões do Brasil, a saber: Região Sul (S); Região Sudeste (SE); Região Nordeste (NE); Região Norte (N); Região Centro-Oeste (CO). Estudo de origem estrangeira: ESTRANG. CRF: Conselho Regional de Farmácia; SES: Secretaria Estadual de Saúde e Anvisa: Agência Nacional de Vigilância Sanitária. 
120

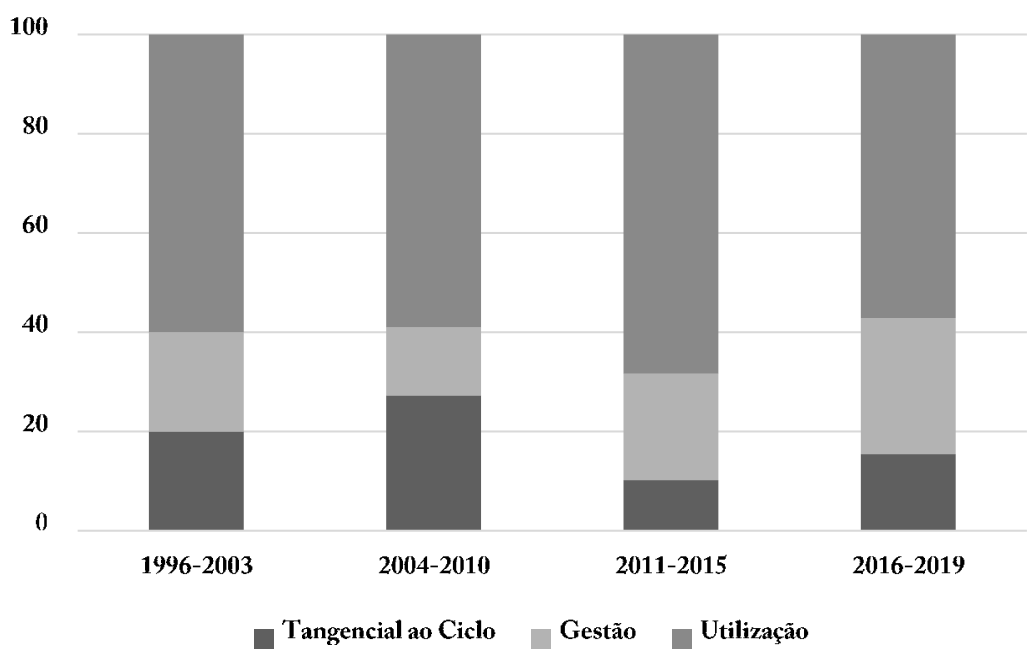

Figura 4. Porcentagem de artigos publicados na Revista Ciência \& Saúde Coletiva, por temática principal do campo teórico-prático da Assistência Farmacêutica, de 1996 a 2019. RC\&SC, 2020.

Fonte: Elaboração própria, 2020.

conhecimento sobre medicamentos (26 artigos) farmacoepidemiologia (26), medicalização e farmaceuticalização (18).

$\mathrm{Na}$ temática principal "tangencial ao ciclo" aparecem 10 temáticas secundárias e 21 especificidades; na "gestão", 18 e 31 especificidades; e na utilização, 24 secundárias e 50 especificidades. $\mathrm{O}$ quadro também mostra a interligação entre dada temática principal, secundária e especificidades, pelo número de artigos relacionados.

\section{Discussão}

É notável o crescimento do tema da AF nas páginas da RC\&SC nos últimos anos. Se houve algum registro de artigos no tema nos anos de 1999, e até 2007, a inflexão na curva se deu pela publicação do Número Temático sobre Medicamentos, em 2008, o que parece ter despertado interesse na área para o tema.

Muitas revistas na área de Ciências Farmacêuticas refletem produção biomédica - seja de bancada, farmacológica ou clínica. Esta organização é acompanhada pelo fato de que a maior parte dos cursos de pós-graduação na área de Ci- ências Farmacêuticas não está no arcabouço da Saúde Coletiva, mas da Farmácia ${ }^{22,23}$.

No entanto, ao longo do tempo, faz se notar o desenvolvimento de estudos voltados para descrição e apresentação de resultados de serviços farmacêuticos no processo de utilização de medicamentos nos serviços de saúde, que podem estar refletindo as discussões e mudanças no campo nos últimos anos. O aumento no número de trabalhos era esperado, considerando-se sobretudo a publicação de novas diretrizes curriculares nacionais para cursos de graduação em Farmácia, em 2002 e 2017. As diretrizes curriculares reforçaram que os conteúdos essenciais para a formação do profissional farmacêutico estivessem relacionados ao processo saúde-doença no âmbito do usuário, da família e da comunidade, contemplando as ciências humanas e sociais ${ }^{24-26}$.

A AF vem ganhando espaço de publicação, seja pelo desenvolvimento do SUS ${ }^{11,27}$, seja pelos temas que impactam na saúde mas também nas contas públicas ${ }^{28,29}$, pelo desenvolvimento da farmacoepidemiologia ${ }^{30,31}$, e pela vocação para discussão de atividades e elaboração de procedimentos voltados a atender às necessidades da população ${ }^{32,33}$. Muito embora a expressão de artigos 
A

$$
\begin{array}{r}
\text { Serviços de AF } \\
\text { Seleção de medicamentos } \\
\text { Satisfação dos usuários } \\
\text { Provisão Pública } \\
\text { Programa Farmácia Popular } \\
\text { Política de Medicamentos }
\end{array}
$$

Papel do profissional farmacêutico

Judicialização de medicamentos

Gerenciamento de resíduos de medicamentos

Farmacoeconomia

Desastres e emergências

Desabastecimento de medicamentos

Compras Públicas

Avaliação de Tecnologias em Saúde

Avaliação da AF

Atenção Primária

Aquisição

Acesso
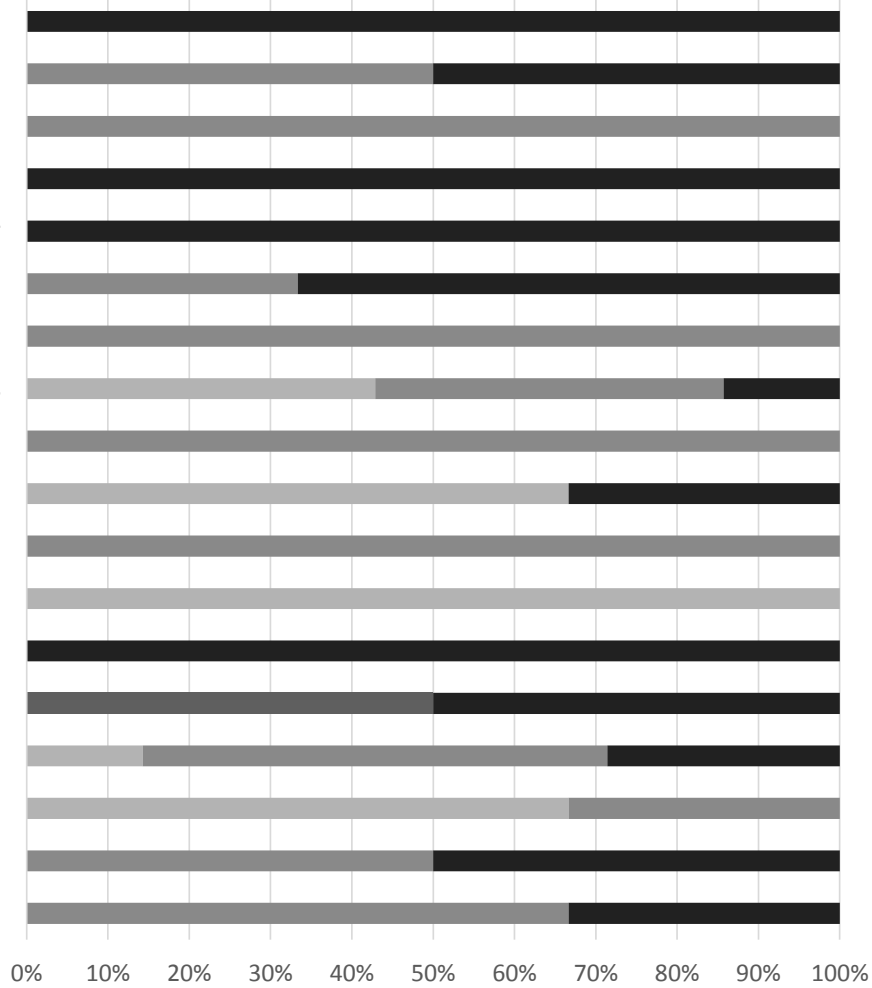

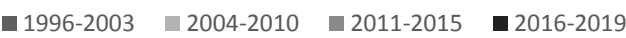

B

Saúde Global / Cooperação Internacional

Regulação sanitária

Registro

Propriedade Intelectual

Propaganda de medicamentos

Política de Medicamentos

Pesquisa e Desenvolvimento

Indústria farmacêutica

Gerenciamento de resíduos de medicamentos

Avaliação de tecnologias em saúde
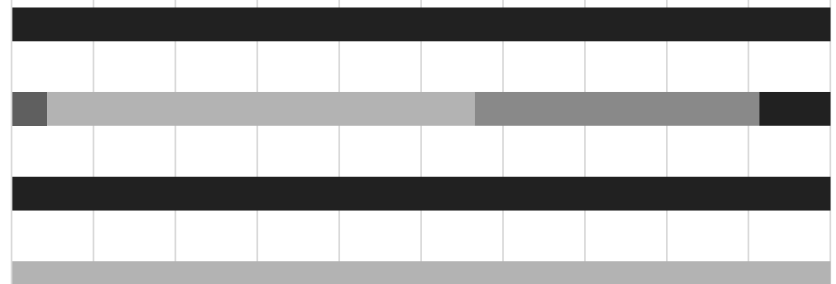

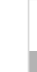

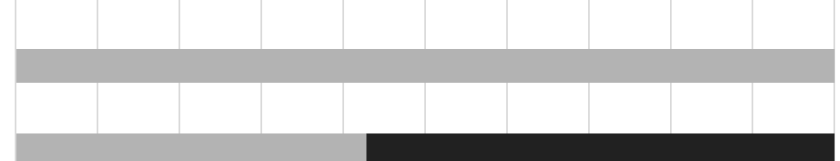

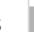

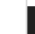

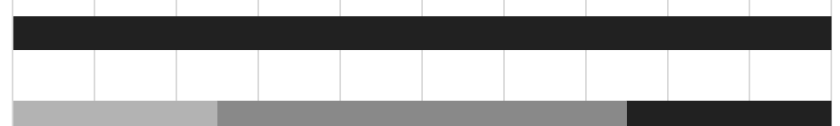

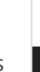

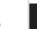

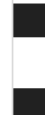

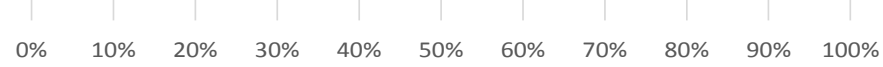

- 1996-2003

Figura 5A e B.Temáticas secundárias de artigos publicados na Revista Ciência \& Saúde Coletiva, por temática principal do campo teórico-prático da Assistência Farmacêutica (AF) (A) Gestão, (B) Tangencial ao Ciclo, (C) Utilização, de 1996 a 2019. RC\&SC, 2020. 


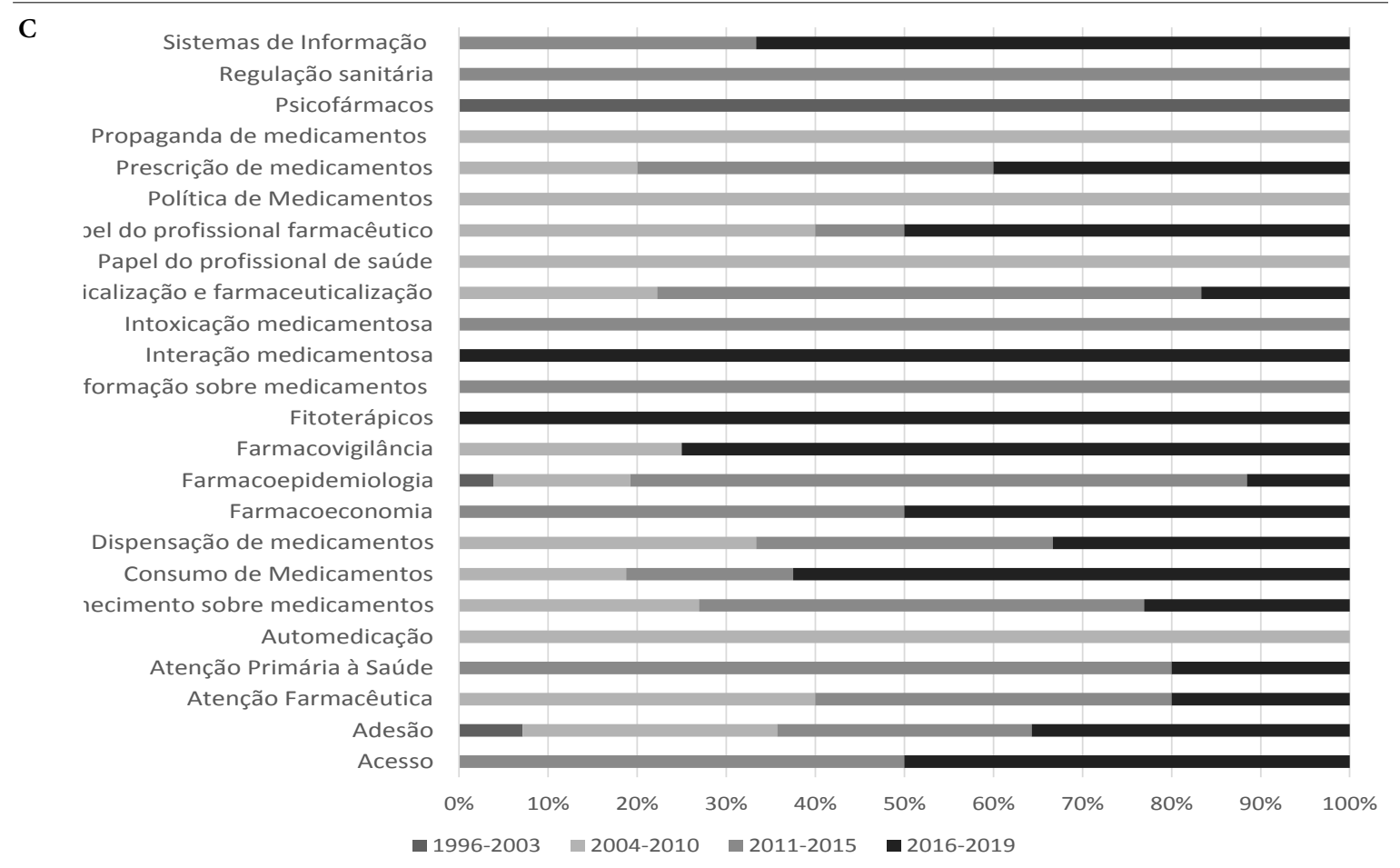

Figura 5C. Temáticas secundárias de artigos publicados na Revista Ciência \& Saúde Coletiva, por temática principal do campo teórico-prático da Assistência Farmacêutica (AF). (A) Gestão, (B) Tangencial ao Ciclo, (C) Utilização, de 1996 a 2019. RC\&SC, 2020.

Fonte: Elaboração própria, 2020.

Quadro 2. Ontologia da Assistência Farmacêutica nas páginas da Revista Ciência \& Saúde Coletiva de 1996 a 2019. RC\&SC, 2020.

\begin{tabular}{|c|c|c|}
\hline $\begin{array}{l}\text { Temática } \\
\text { Principal }\end{array}$ & Temática Secundária & Especificidade \\
\hline \multirow{10}{*}{$\begin{array}{l}\text { Aspectos } \\
\text { tangenciais } \\
\text { ao Ciclo da } \\
\text { Assistência } \\
\text { Farmacêutica } \\
(43)\end{array}$} & $\begin{array}{l}\text { Avaliação de Tecnologia em Saúde } \\
\text { (2) }\end{array}$ & Incorporação de Medicamentos (2) \\
\hline & $\begin{array}{l}\text { Gerenciamento de resíduos de } \\
\text { medicamentos (1) }\end{array}$ & Marcos e Conceitos (1) \\
\hline & Indústria Farmacêutica (4) & Fitoterápicos (2); Genéricos (1) Biotecnologia (1) \\
\hline & Pesquisa e Desenvolvimento (1) & Antimalárico (1) \\
\hline & Política de Medicamentos (7) & $\begin{array}{l}\text { Antirretrovirais (2); Genéricos (1); Marcos e Conceitos (2); Saúde } \\
\text { Global (2) }\end{array}$ \\
\hline & Propaganda de Medicamentos (1) & Marcos e Conceitos (1) \\
\hline & Propriedade Intelectual (1) & Antirretrovirais (1) \\
\hline & Registro (1) & Incorporação de Medicamentos (1) \\
\hline & Regulação Sanitária (23) & $\begin{array}{l}\text { Comercialização de Medicamentos (1); Controle de Qualidade } \\
\text { de Medicamentos (1); Farmacovigilância (1); Genéricos (1); } \\
\text { Gerenciamento de Resíduos de Medicamentos (2); Informação } \\
\text { sobre Medicamentos (2); Marcos e Conceitos (2); Medicamentos } \\
\text { Manipulados (2); Nanotecnologia (1); Psicofármacos (1); Propaganda } \\
\text { de Medicamentos (5); Registro (2); Rotulagem de Medicamentos (1); } \\
\text { Serviços de Assistência Farmacêutica (1) }\end{array}$ \\
\hline & $\begin{array}{l}\text { Saúde Global/Cooperação } \\
\text { Internacional (2) }\end{array}$ & Antirretrovirais (1); Propriedade Intelectual (1) \\
\hline
\end{tabular}


Quadro 2. Ontologia da Assistência Farmacêutica nas páginas da Revista Ciência \& Saúde Coletiva de 1996 a 2019. RC\&SC, 2020.

\begin{tabular}{|c|c|c|}
\hline $\begin{array}{l}\text { Temática } \\
\text { Principal }\end{array}$ & Temática Secundária & Especificidade \\
\hline \multirow{18}{*}{$\begin{array}{l}\text { Aspectos de } \\
\text { Gestão (56) }\end{array}$} & Acesso (3) & Hipertensão e/ou Diabetes (2); Programa Farmácia Popular (1) \\
\hline & Aquisição (2) & Compras Públicas (2) \\
\hline & Atenção Primária à Saúde (3) & Avaliação Assistência Farmacêutica (1); Marcos e Conceitos (2) \\
\hline & $\begin{array}{l}\text { Avaliação Assistência Farmacêutica } \\
(7)\end{array}$ & $\begin{array}{l}\text { Atenção Farmacêutica (1); Componente Especializado da Assistência } \\
\text { Farmacêutica (2); Farmácia Hospitalar (1); Marcos e Conceitos (1); } \\
\text { Serviços de Assistência Farmacêutica (2) }\end{array}$ \\
\hline & $\begin{array}{l}\text { Avaliação de Tecnologia em Saúde } \\
(2)\end{array}$ & Marcos e Conceitos (1); Guia de Prática Clínica e Terapêutica (1) \\
\hline & Compras Públicas (1) & Hepatite C (1) \\
\hline & $\begin{array}{l}\text { Desabastecimento de } \\
\text { Medicamentos (1) }\end{array}$ & Acesso (1) \\
\hline & Desastres e Emergências (1) & Preparação (1) \\
\hline & Farmacoeconomia (3) & Marcos e Conceitos (2); Programa Farmácia Popular (1) \\
\hline & $\begin{array}{l}\text { Gerenciamento de Resíduos de } \\
\text { Medicamentos (2) }\end{array}$ & Atenção Primária à Saúde (1); Marcos e Conceitos (1) \\
\hline & $\begin{array}{l}\text { Judicialização de Medicamentos } \\
(8)\end{array}$ & $\begin{array}{l}\text { Antineoplásicos (1); Direito à Saúde (1); Doenças Raras (3); Insulina } \\
\text { (1); Itinerário Terapêutico (1); Provisão de Medicamentos (1) }\end{array}$ \\
\hline & $\begin{array}{l}\text { Papel do Profissional Farmacêutico } \\
(1)\end{array}$ & Ensino de Farmácia (1) \\
\hline & Política de Medicamentos (12) & $\begin{array}{l}\text { Antimicrobiano (1); Componente Especializado da Assistência } \\
\text { Farmacêutica (2); Doenças Raras (1); Fitoterápico (1); Hepatite C (1); } \\
\text { Marcos e Conceitos (4); Programa Farmácia Popular (1); Serviços de } \\
\text { Assistência Farmacêutica (1) }\end{array}$ \\
\hline & Programa Farmácia Popular (1) & Anti-hipertensivo (1) \\
\hline & Provisão Pública (2) & Dislipidemia (1); Medicamentos Estratégicos (1) \\
\hline & Satisfação do Usuário (1) & Dispensação de Medicamentos (1) \\
\hline & Seleção de Medicamentos (2) & Medicamentos Essenciais (2) \\
\hline & $\begin{array}{l}\text { Serviços de Assistência } \\
\text { Farmacêutica (4) }\end{array}$ & $\begin{array}{l}\text { Atenção Primária à Saúde (1); Antineoplásicos (1); Saúde Mental (1), } \\
\text { Regionalização (1) }\end{array}$ \\
\hline
\end{tabular}

sobre AF esteja em crescimento em outros periódicos nacionais, as revistas de Saúde Coletiva, como a RC\&SC, ainda concentram a produção voltada aos aspectos ditos "sociais" das Ciências Farmacêuticas. Percebe-se ainda que a RC\&SC se revela como um espaço de importante divulgação da temática, tendo sido responsável por um grande número de artigos, mantendo uma proporção de 5 a $10 \%$ de artigos em AF, frente ao total publicado, ao longo dos últimos onze anos.

No contexto internacional, há uma série de periódicos voltados para a produção das Ciências Farmacêuticas e outros tantos para a Saúde Pública. Assim como no país, a produção científica no tema tende a se dicotomizar entre biomedicina e ciências sociais. No entanto, um dos aspec- tos que ainda desafia a apropriação do tema entre países e que influi na publicação do campo da AF, são as diferenças conceituais relacionadas ao termo AF, e adotadas nos descritores utilizados no exterior e no Brasil. Assistência Farmacêutica tem sido traduzida por uma variedade de termos. Uma primeira tradução para língua inglesa nos remete a pharmaceutical care. Entretanto, a literatura internacional o aponta como um elemento do Cuidado, que se relaciona aos aspectos da interação entre o profissional farmacêutico e o paciente, contribuindo para sua qualidade de vida $^{34}$. Nesse sentido, percebe-se que o termo remete à Atenção Farmacêutica. Por outro lado, a livre versão do termo para o inglês, retorna pharmaceutical assistance. Este termo na língua 
Quadro 2. Ontologia da Assistência Farmacêutica nas páginas da Revista Ciência \& Saúde Coletiva de 1996 a 2019. RC\&SC, 2020.

\begin{tabular}{|c|c|c|}
\hline $\begin{array}{l}\text { Temática } \\
\text { Principal }\end{array}$ & Temática Secundária & Especificidade \\
\hline \multirow{23}{*}{$\begin{array}{l}\text { Aspectos de } \\
\text { Utilização } \\
(161)\end{array}$} & Acesso (2) & Genéricos (1); Fitoterápicos (1) \\
\hline & Adesão Medicamentosa (14) & $\begin{array}{l}\text { Antiparkinsonianos (1); Antirretrovirais (4); Doenças Raras (1); } \\
\text { Hipertensão e/ou Diabetes (2); Idosos (3); Marcos e Conceitos (2); } \\
\text { Violência Sexual (1) }\end{array}$ \\
\hline & Atenção Farmacêutica (5) & $\begin{array}{l}\text { Marcos e Conceitos (2); Serviços de Assistência Farmacêutica (1); } \\
\text { Idosos (1); Satisfação do Usuário (1) }\end{array}$ \\
\hline & Atenção Primária à Saúde (5) & $\begin{array}{l}\text { Fitoterápico (3); Itinerário Terapêutico (1); Hipertensão e/ou Diabetes } \\
(1)\end{array}$ \\
\hline & Automedicação (4) & $\begin{array}{l}\text { Analgésicos (1); Idosos (1); Estudantes (1); Comercialização de } \\
\text { Medicamentos (1) }\end{array}$ \\
\hline & $\begin{array}{l}\text { Conhecimento sobre } \\
\text { medicamentos }(26)\end{array}$ & $\begin{array}{l}\text { Adaptação transcultural (4); Adesão (1); Antiinflamatório (1); } \\
\text { Antimalárico (1); Antimicrobiano (1); Antirretrovirais (1); } \\
\text { Armazenamento (1); Atenção Primária à Saúde (3); Contraceptivos } \\
\text { (1); Doenças Raras (1); Fitoterápicos (1); Genéricos (1); Hipertensão e/ } \\
\text { ou Diabetes (2); Idosos (2); Pediatria/Neonatologia (1); Prescrição (1); } \\
\text { Promoção da Saúde(1); Psicofármacos (2) }\end{array}$ \\
\hline & Consumo de Medicamentos (16) & $\begin{array}{l}\text { Adultos (2); Atenção Primária à Saúde (1); Automedicação (1); } \\
\text { Genéricos (1); Idosos (3); Pediatria/Neonatologia (2); Propaganda de } \\
\text { Medicamentos (1); Psicofármacos (5) }\end{array}$ \\
\hline & Dispensação de Medicamentos (3) & Marcos e Conceitos (2); Atenção Primária a Saúde (1) \\
\hline & Farmacoeconomia (2) & Anorexígenos (1); Artrite Reumatoide (1) \\
\hline & Farmacoepidemiologia (26) & $\begin{array}{l}\text { Anorexígenos (1); Antimicrobiano (2); Antirretrovirais (1); Atenção } \\
\text { Primária à Saúde (2); Contraceptivos (2); Gênero (1); Gestantes (2); } \\
\text { Hipertensão e/ou Diabetes (2); Idosos (3); Intoxicação Medicamentosa } \\
\text { (1); Psicofármacos (3); Talidomida (1); Marcos e Conceitos (2); } \\
\text { Pediatria/Neonatologia (2); Trabalhadores na Saúde (1) }\end{array}$ \\
\hline & Farmacovigilância (4) & $\begin{array}{l}\text { Psicofármacos (1); Interação Medicamentosa (1); Intoxicação } \\
\text { Medicamentosa (1); Idosos (1) }\end{array}$ \\
\hline & Fitoterápicos (1) & Gestantes (1) \\
\hline & $\begin{array}{l}\text { Informação sobre Medicamentos } \\
(1)\end{array}$ & Metilfenidato (1) \\
\hline & Interação Medicamentosa (5) & Idosos (4); Farmacovigilância (1) \\
\hline & Intoxicação Medicamentosa (1) & Gênero (1) \\
\hline & $\begin{array}{l}\text { Medicalização e } \\
\text { Farmaceuticalização (18) }\end{array}$ & $\begin{array}{l}\text { Adolescente (1); Anorexígenos (2); Antirretrovirais (1); Automedicação } \\
\text { (1); Contraceptivos (1); Cuidados Paliativos (1); Gênero (1); Marcos e } \\
\text { Conceitos (4); Metilfenidato (1); Misoprostol (1); Psicofármacos (3); } \\
\text { Representação Social do Medicamento (1) }\end{array}$ \\
\hline & $\begin{array}{l}\text { Papel do Profissional Farmacêutico } \\
(10)\end{array}$ & $\begin{array}{l}\text { Atenção Primária à Saúde (4); Marcos e Conceitos (4); Saúde Mental } \\
\text { (1); Satisfação do Usuário (1) }\end{array}$ \\
\hline & Política de Medicamentos (1) & Doenças Raras (1) \\
\hline & Prescrição de Medicamentos (10) & $\begin{array}{l}\text { Antimicrobianos (2); Avaliação da Assistência Farmacêutica (1); } \\
\text { Farmácia Hospitalar (1); Conhecimentos sobre Medicamentos (1); } \\
\text { Fitoterápicos (1); Idosos (1); Marcos e Conceitos (1); Psicofármacos } \\
\text { (1); Regulação Sanitária (1) }\end{array}$ \\
\hline & Propaganda de Medicamentos (1) & Prescrição de Medicamentos (1) \\
\hline & Psicofármacos (1) & Política de Medicamentos (1) \\
\hline & Regulação Sanitária (1) & Misoprostol (1) \\
\hline & Sistema de Informação (3) & Farmacovigilância (2); Intoxicação Medicamentosa (1) \\
\hline
\end{tabular}

Fonte: Elaboração própria, 2020. 
inglesa remete a outro conceito, o de "benefício farmacêutico", sendo, portanto, completamente inadequado como descritor do tema.

No contexto das Américas, no âmbito das discussões sobre sistemas de saúde locais, surge o termo pharmaceutical services ${ }^{35}$. Ainda que o termo não obtenha completa unanimidade, pois pode ser relacionado a serviços de forma pontu$\mathrm{al}^{36-38}$, é necessário destacar que a Bireme adota como sinonímia do termo Assistência Farmacêutica os termos pharmaceutical services (inglês) e servicios farmacéuticos (espanhol) ${ }^{39}$. Deste modo, ainda que os termos sejam aproximados e não idênticos, é necessário o esforço de alinhar-se a uma sinonímia comum, oficial. O uso dos mesmos descritores é estratégia para consolidação do campo e comunhão na publicação científica. Nas páginas da RC\&SC, este esforço vem apresentando retorno, e raros foram os episódios de má tradução ou má versão do termo AF, mormente depois de 2010.

Os artigos de tipo tema-livre, e mais recentemente os artigos originais, têm expressão, refletindo a prática em instituições e unidades de saúde, hospitais, e práticas de gestão. O campo da AF ainda conta com relativamente poucas revisões de cunho mais específico, sejam sistemáticas, narrativas, de escopo, ou revisões qualitativas. Esse pode ser um sintoma do crescimento recente do campo e da necessidade ainda não atendida, de amealhar suficiente quantidade de referências, em um mesmo tema, para proporcionar uma revisão robusta ${ }^{40-44}$.

O inglês vem crescendo como idioma de artigos apresentados à publicação. A estratégia da RC\&SC e de outras tantas, a partir de determinação do SciELO, de traduzir artigos e de aceitar artigos já escritos em inglês, espanhol, tem ajudado não apenas a disseminar o conhecimento, mas a situar os autores em uma posição de melhor diálogo com pares e parceiros internacionais. Os aspectos trazidos por artigos da AF estão cada vez mais adotando temáticas que encontram identidade compartilhada no exterior, como farmacoepidemiologia, alocação de recursos, avaliação de tecnologias, entre outros. Além disso, o estudo dos avanços do SUS - direito à saúde e acesso universal, motivam o estudo das disparidades trazidas pelo contexto e fenômenos disruptivos ou distorções, geradores de iniquidades - como a judicialização para acesso a medicamentos - e que despertam o interesse da comunidade internacional ${ }^{45-48}$.

As instituiçõoes acadêmicas, como universidades e a Fiocruz, abrigam os primeiros autores de forma preponderante, mostrando que o tema está disseminado e gera produção de conhecimento. No entanto, são as universidades públicas que dominam o cenário das publicações em AF. As instituições estrangeiras, bem como autores estrangeiros, vêm contribuindo pouco ao longo do tempo.

A produção ainda está concentrada na principal região de produção científica no país, o Sudeste. Essa concentração reflete outras tantas "concentrações", como grupos de pesquisa, financiamento da pesquisa, centros de tomada de decisão e pujança na alocação de recursos para a saúde e para a $\mathrm{AF}^{49}$.

Em todos os períodos o tema da Utilização foi o que apresentou sempre maior proporção dentre as publicações. A utilização envolve questões muitas vezes relacionadas a características dos medicamentos ou mesmo dos profissionais - prescritores, dispensadores - e pacientes, e nesse sentido seu desenvolvimento parte, principalmente, da necessidade de compreensão sobre as consequências positivas e/ou negativas do uso de medicamentos, da relação com a regulação sanitária, além da real obrigação de se fornecer subsídios para o manejo adequado desses insumos.

O primeiro período de observação envolve o início da AF no recém criado SUS e a publicação da PNM. Não é por coincidência que artigos de temas livres, voltados para marcos teóricos e conceitos foram mais frequentes. É recente a história do arcabouço normativo que delineia a assistência farmacêutica em nosso país. Apesar da PNM, de 1998, todas as normas infralegais que passaram a reger a $\mathrm{AF}$ vieram em período posterior. A crise da fraude de medicamentos, naquele mesmo ano, estabeleceu um foco temático nos temas de Vigilância Sanitária e Regulação de Medicamentos. O sistema, desafiado a reestruturar-se, voltou-se para a garantia de qualidade de insumos e produtos, obrigando a readequação dos serviços farmacêuticos públicos e privados a fim de garantir a origem dos produtos ofertados ao público ${ }^{50}$. Esses fatos trouxeram temas da regulação para as páginas da RC\&SC.

Outra fase tem como exemplo o pacto pela Saúde, lançado em $2006^{51,52}$. O Pacto trouxe um conjunto de reformas institucionais para o SUS, com uma série de inovações nos processos e instrumentos de gestão, incluindo aí o financiamento da AF. Isto suscitou a apropriação, tanto por gestores, quanto por acadêmicos, das novas regras e de seus "impactos" sobre a população e sobre o sistema.

No segundo período de observação, 20042010, o país vivenciou a expansão do SUS e o 
estabelecimento dos programas de AF - os trabalhos originais passam a ter expressão. Nesse sentido, trabalhos que abordam temas ligados aos Componentes para o financiamento da AF, trabalhos sobre programas de acesso a medicamentos, tais como Farmácia Popular, e também temas como a judicialização, só passaram a ser publicados a partir do delineamento dos limites e possibilidades da AF e do SUS. Se o tema da Utilização continua sempre dominando, a Gestão passa a ter importância relativa à medida que o tempo passa, uma vez que reflete a prática profissional na organização do SUS ${ }^{53-57}$. Durante o período de 2011-2015 a AF viveu a turbulência da modificação conceitual da Relação Nacional de Medicamentos Essenciais (Rename), tendo como consequências, entre outras, sua redução, de conjunto de medicamentos de baixa, média e alta complexidade para atender às necessidades sanitárias, a um agregado de listas de financiamento de medicamentos sob demanda ${ }^{55}$.

O temas tangenciais ao Ciclo, como regulação sanitária, propriedade intelectual, que foram estruturantes ao campo em um primeiro momento, como na luta por acesso a medicamentos de Pessoas Vivendo com HIV/Aids, por exemplo, diminuem proporcionalmente em número de publicações, e surgem, nesta mesma temática, outros temas, como Saúde Global e Cooperação Internacional ${ }^{58,59}$. Destaca-se, no entanto, o último quadriênio examinado foi observado um maior número de estudos publicados nessa grande temática principal, o que pode significar que estes temas mais inovadores e globalizados do campo da AF serão os mais discutidos e explorados nos próximos anos.

A ontologia ${ }^{60}$ revela toda a diversidade temática da AF nas páginas da RC\&SC. Reúne temáticas secundárias variadas e recorrentes nos artigos, bem como novas temáticas, como a Saúde Global/Cooperação Internacional e outras que passam a ter uma presença mais marcante, como a farmacoepidemiologia, a farmacoeconomia, a avaliação de tecnologias em saúde, a farmaceuticalização e medicalização; além disso há os temas emergentes, como emergências sanitárias e desastres. As especificidades são inúmeras e apresentam a característica de serem transversais aos temas - podem ser discutidas ou abordadas em várias temáticas secundárias e principais. É esta variedade e esse conjunto de "olhares" que promove a disseminação de variados pontos de vista sobre um mesmo assunto, trazendo elaboração, solidez conceitual e apontando novos caminhos de análise e novo conhecimento. A ontologia da AF nos mostra que o campo não é estático, é dinâmico e, mais importante, está integrado, podendo oferecer utilidade para averiguação de relações de interdependência entre temas e para futuras indexações de termos próprios da AF.

Este estudo contou com algumas limitações. Todo o grupo de pesquisadores foi responsável pelo resgate dos trabalhos e, ainda que tenha havido um processo cuidadoso de busca e de deliberação sobre dúvidas em relação aos artigos elegíveis, sem dúvida houve alguma diversidade de critérios. Espera-se que a cooperação no trabalho e os ajustes em grupo tenham possibilitado uma adequada resolução dessas divergências. Outro desafio se deu no momento de realizar a classificação em temáticas principais, secundárias e especificidades. A visão de cada um sobre os temas e suas interdependências obrigou a um julgamento objetivo de classificação, o que pode ter resultado em uma decisão reducionista acerca dos temas dos trabalhos. Mesmo assim, estima-se que a diversidade do campo tenha sido retratada pela ontologia.

Por fim, uma limitação foi a busca inicial pelo site do SciELO. Os descritores utilizados, inicialmente, não favoreceram uma busca fidedigna. Houve uma série de falhas de informação; o êxito da busca só se confirmou quando refeita e validada pelo site da RC\&SC. Esta situação mostra, por sua vez, a utilidade e fidedignidade do sítio de internet da RC\&SC, como recurso futuro para estudos de revisão que usem os números da Revista.

\section{Conclusão}

Ao longo dos últimos 24 anos, o estudo refletiu a expansão e dinamismo do campo teórico-prático da AF nas páginas da RC\&SC. Houve crescimento real da AF, como grande temática, no bojo da publicação, ao longo do tempo. Ainda que com a participação de todas as regiões brasileiras, há que se trabalhar para aumentar a participação de autores do Norte, do Nordeste e do Centro-Oeste e ainda, autores do exterior. As universidades públicas foram majoritariamente as instituições que mais contribuíram para este avanço, como também a Fiocruz.

Os temas publicados se inseriram dentro de grandes temáticas principais, quais sejam, Utilização de Medicamentos, Gestão e Temas Tangenciais ao Ciclo da AF; temas secundários e especificidades complementaram a classificação de estudos publicados, o que possibilitou verificar a 
diversidade e a interrelação entre os temas, explícitos na ontologia produzida.

Diferentes fenômenos que tiveram impacto na saúde pública ao longo desses anos apresentaram maior ou menor presença dentro da publicação em AF na RC\&SC. Vimos que a AF refletiu o conhecimento emergente dentro do escopo dos medicamentos e da terapêutica medicamentosa. Foi a AF que trouxe à tona o tema da judicialização; foi a AF que trouxe para discussão os temas do acesso a medicamentos e da propriedade intelectual. Aguardar-se-á novos e desafiantes trabalhos no tema, direcionados à RC\&SC.

A AF é um campo em expansão. Traz a complexidade da política pública aliada às atividades gerenciais e de ponta, no cuidado em saúde à população. Produz uma gama variada de interrelações e espera-se que essas venham a se expressar cada vez mais na publicação científica.

\section{Colaboradores}

Todos os autores participaram do trabalho em todas as suas etapas, incluindo sua concepção e planejamento, coleta e análise dos dados, assim como da elaboração do texto e figuras, e da revisão e aprovação da versão final do manuscrito. 


\section{Referências}

1. Kostriba MSJ, Alwarafi A, Vlceka J. Social Pharmacy as a Field of Study in Undergraduate Pharmacy Education. Indian J Pharm Educ Res 2014; 48(1):6-12.

2. Sorensen EW, Mount JK, Christensen ST. The concept of social pharmacy. The Chronic Ill 2003; 7:8-11.

3. Brasil. Lei ${ }^{\circ} 8.080$, de 19 de setembro de 1990. Dispõe sobre as condições de promoção, proteção e recuperação da saúde, a organização e o funcionamento dos serviços correspondentes e dá outras providencias. Diário Oficial da União 1990; 19 set.

4. Brasil. Portaria ${ }^{\circ} 3.916,30$ de outubro de 1998. Aprova a Política Nacional de Medicamentos. Diário Oficial da União 1998; 10 nov.

5. Brasil. Portaria $\mathrm{n}^{\circ} 176$, de 8 de março de 1999. Estabelece critérios e qualificação dos municípios e estados ao Incentivo à Assistência Farmacêutica Básica e define valores a serem transferidos. Diário Oficial da União 1999; 11 mar

6. Brasil. Resolução $n^{\circ}$ 338, de 06 de maio de 2004. Aprova a Política Nacional de Assistência Farmacêutica. Diário Oficial da União 2004; 20 maio.

7. Quick JD, Hogerzeil HV, Rankin JR, Dukes MNG, Laing R, Garnett A, O'Connor RW, editores. Managing drug supply: the selection, procurement, distribution, and use of pharmaceuticals. Connecticut: Kumarian Press; 1997.

8. Osorio-de-Castro CGS, Luiza VL, Castilho SR, Oliveira MA, Jaramillo NM, organizadores. Assistência farmacêutica: gestão e prática para profissionais da saúde. Rio de Janeiro: Editora Fiocruz; 2014.

9. Marin N, Luiza VL, Osorio-de-Castro CGS, Machadodos-Santos S, organizadores. Assistência farmacêutica para gerentes municipais. Brasília: OPAS/OMS; 2003.

10. Osmo A, Schraiber LB. O campo da Saúde Coletiva no Brasil: definições e debates em sua constituição. Saúde Soc 2015; 24(Supl. 1):205-218.

11. Bermudez JAZ, Esher A, Osorio-de-Castro CGS, Vasconcelos DMM, Chaves GC, Oliveira MA, Silva RM, Luiza VL. Assistência Farmacêutica nos 30 anos do SUS na perspectiva da integralidade. Cien Saude Colet 2018; 23(6):1937-1949.

12. Grant MJ, Booth A. A typology of reviews: an analysis of 14 review types and associated methodologies. Health Info Libr J 2009; 26(2):91-108.

13. Peters MDJ, Godfrey CM, Khalil H, McInerney P, Parker D, Soares CB. Guidance for conducting systematic scoping reviews. Int J Evid Based Healthc 2015; 13(3):141-146.

14. Brasil. Decreto ${ }^{\circ} 7.508$, de 28 de junho de 2011. Regulamenta a Lei no 8.080, de 19 de setembro de 1990, para dispor sobre a organização do Sistema Único de Saúde - SUS, o planejamento da saúde, a assistência à saúde e a articulação interfederativa, e dá outras providencias. Diário Oficial da União 2011; 29 jun.

15. Conselho Nacional dos Secretários de Saúde (CONASS). A Lei no 141/2012 e os Fundos de Saúde. Brasília: CONASS; 2013.
16. Brasil. Portaria ${ }^{\circ} 1.554$, de 30 de julho de 2013. Dispõe sobre as regras de financiamento e execução do Componente Especializado da Assistência Farmacêutica no âmbito do Sistema Único de Saúde (SUS). Diário Oficial da União 2013; 31 jul.

17. Brasil. Portaria $\mathrm{n}^{\circ} 1.555$, de 30 de julho de 2013. Dispõe sobre as regras de financiamento e execução do Componente Básico da Assistência Farmacêutica no âmbito do Sistema Único de Saúde (SUS). Diário Oficial da União 2013; 31 jul.

18. Brasil. Portaria $\mathrm{n}^{\circ} 2.084$, de 26 de outubro de 2005. Estabelece normas, responsabilidades e recursos a serem aplicados no financiamento da Assistência Farmacêutica na Atenção Básica e define o elenco mínimo obrigatório de medicamentos. Diário Oficial da União 2005; 10 nov.

19. Brasil. Portaria $\mathrm{n}^{\circ} 3.193$, de 9 de dezembro de 2019. Altera a Portaria de Consolidação n ${ }^{\circ}$ 6/GM/MS, de 28 de setembro de 2017, para dispor sobre o financiamento do Componente Básico da Assistência Farmacêutica no âmbito do Sistema Único de Saúde (SUS). Diário Oficial da União 2019; 10 dez.

20. Vieira FS. Implicações de decisões e discussões recentes para o financiamento do Sistema Único de Saúde. Saúde Debate 2016; 40(109):187-199.

21. Oliveira MA, Bermudez JAZ, Osorio-de-Castro CGS. Assistência farmacêutica e acesso a medicamentos. Rio de Janeiro: Editora Fiocruz; 2007.

22. Almeida RB, Mendes DHC, Dalpizzol PA. Ensino farmacêutico no Brasil na perspectiva de uma formação clínica. Rev Cien Farm Básica Apl 2014; 35(3):347-354.

23. Angonesi D, Sevalho G. Atenção Farmacêutica: fundamentação conceitual e crítica para um modelo brasileiro. Cien Saude Colet 2010; 15(Supl. 3):3603-3614.

24. Brasil. Resolução CNE/CES n ${ }^{\circ}$ 2, de 19 de fevereiro de 2002. Institui Diretrizes Curriculares Nacionais do Curso de Graduação em Farmácia. Diário Oficial da União 2002; 4 mar.

25. Brasil. Resolução CNE/CES n ${ }^{\circ}$ 6, de 19 de outubro de 2017. Institui Diretrizes Curriculares Nacionais do Curso de Graduação em Farmácia. Diário Oficial da União 2017; 20 out.

26. Conselho Federal de Farmácia (CFF). Serviços farmacêuticos diretamente destinados ao paciente, à família e à comunidade: contextualização e arcabouço conceitual. Brasília: CFF; 2016.

27. Gadelha CAG, Temporão JG. Desenvolvimento, Inovação e Saúde: a perspectiva teórica e política do Complexo Econômico-Industrial da Saúde. Cien Saude Colet 2018; 23(6):1891-1902.

28. Caetano R, Hauegen RC, Osorio-de-Castro CGS. A incorporação do nusinersena no Sistema Único de Saúde: uma reflexão crítica sobre a institucionalização da avaliação de tecnologias em saúde no Brasil. Cad Saúde Pública 2019; 35(8):e00099619.

29. Moraes EL, Osorio-de-Castro CGS, Caetano R. Compras federais de antineoplásicos no Brasil: análise do mesilato de imatinibe, trastuzumabe e L-asparaginase, 2004-2013. Physis 2016; 26(4):1357-1382. 
30. Bégaud B. A history of pharmacoepidemiology. The rapie 2019; 74(2):175-179.

31. Sommet A, Pariente A. Methods in pharmacoepidemiology. Therapie 2019; 74(2):187-197.

32. Magarinos-Torres R, Pepe VLE, Osorio-de-Castro CGS. Estruturação da assistência farmacêutica: plano de ação para a seleção de medicamentos essenciais. Cad Saude Colet 2013; 21(2):188-196.

33. Steiner L, Maraj D, Woods H, Jarvis J, Yaphe H, Adekoya I, Bali A, Persaud N. A comparison of national essential medicines lists in the Americas. Rev Panam Salud Publica 2020; 44:e5.

34. Hepler CD, Strand LM. Opportunities and responsibilities in pharmaceutical care. Am J Hosp Pharm 1990; 47(3):533-543.

35. Pan American Health Organization (PAHO). Guidelines for the Development of Pharmaceutical Services in Primary Health Care. Washington: PAHO/WHO; 2011.

36. Bradley F, Elvey R, Ashcroft DM, Hassell K, Kendall J, Sibbald B, Noyce P. The challenge of integrating community pharmacists into the primary health care team: A case study of local pharmaceutical services (LPS) pilots and interprofessional collaboration. J Interprof Care 2008; 22(4):387-398.

37. Sczupak CA, Conrad WF. Relationship between patient-oriented pharmaceutical services and therapeutic outcomes of ambulatory patients with diabetes mellitus. Am J Hosp Pharm 1977; 34(11):1238-1242.

38. Singhal PK, Raisch DW, Gupchup GV. The Impact of Pharmaceutical Services in Community and Ambulatory Care Settings: Evidence and Recommendations for Future Research. Ann Pharmacother 1999; 33(12):1336-1255.

39. Descritores em Ciências da Saúde (DeCS) [Internet]. Versão 2020. São Paulo: BIREME/OPAS/OMS; 2020.

40. Becker MW, Lunardelli MJM, Tovo CV, Blatt CR. Drug and herb-induced liver injury: A critical review of Brazilian cases with proposals for the improvement of causality assessment using RUCAM. Ann Hepatol 2019; 18(5):742-750.

41. Domingues I. O sistema de comunicação da ciência e o taylorismo acadêmico: questionamentos e alternativas. Estud $A v$ 2014; 28(82):225-250.

42. Gomes VP, Silva MT, Galvão TF. Prevalência do consumo de medicamentos em adultos brasileiros: uma revisão sistemática. Cien Saude Colet 2017; 22(8):2615-2626.

43. Kentab BY, Barry HE, Al-Aqeel SA, Hughes CM. A systematic review of pharmacists' interventions to support medicines optimisation in patients with visual impairment. Int J Clin Phar 2019; 41(6):1400-1407.

44. Wright DJ, Maskrey V, Blyth A, Norris N, Alldred DP, Bond CM, Desborough J, Hughes CM, Holland RC. Systematic review and narrative synthesis of pharmacist provided medicines optimization services in care homes for older people to inform the development of a generic training or accreditation process. Intl Pharm Pract 2020; 28(3):207-219.
45. Chagas VO, Provin MP, Mota PAP, Guimarães RA Amaral RG. Institutional strategies as a mechanism to rationalize the negative effects of the judicialization of access to medicine in Brazil. BMC Health Serv Res 2020; 20(1):80.

46. Paula EA, Silva RAM, Siqueira PSF, Melo DO. Registro de medicamentos com indicação agnóstica já é realidade no Brasil, o que significa para a judicialização? Cad Ibero Am Direito Sanit 2019; 8(4):145-155.

47. Pedro EM, Caetano R, Teodoro CRS, Steffen RE, Silva RM. Incorporação de medicamentos sem registro sanitário no SUS: um estudo das recomendações da Comissão Nacional de Incorporação de Tecnologias no período 2012-2016. Vigil Sanit Debate 2018; 6(3):12-21.

48. Rutter PM, Harrison T. Differential diagnosis in pharmacy practice: Time to adopt clinical reasoning and decision making. Res Social Adm Pharm 2020; 16(10):1483-1486.

49. Silva RM, Caetano R. Um exame dos fluxos financeiros do Ministério da Saúde em pesquisa e desenvolvimento (2003-2005), segundo a Agenda Nacional de Prioridades de Pesquisa em Saúde. Cad Saúde Pública 2011; 27(4):687-700

50. Brasil. Portaria $\mathrm{n}^{\circ} 802$, de 8 de outubro de 1998. Institui o Sistema de Controle e Fiscalização em toda a cadeia dos produtos farmacêuticos. Diário Oficial da União 1998; 9 out.

51. Brasil. Portaria $\mathrm{n}^{\circ} 399$, de 22 de fevereiro de 2006. Divulga o Pacto pela Saúde 2006 - Consolidação do SUS e aprova as Diretrizes Operacionais do referido Pacto. Diário Oficial da União 2006; 23 fev.

52. Vasconcelos DMM, Chaves GC, Azeredo TB, Silva RM. Política Nacional de Medicamentos em retrospectiva: um balanço de (quase) 20 anos de implementação. Cien Saude Colet 2017; 22(8):2609-2614.

53. Catanheide ID, Lisboa ES, Souza LEPF. Características da judicialização do acesso a medicamentos no Brasil: uma revisão sistemática. Physis 2016; 26(4):13351356.

54. Pepe VLE, Figueiredo TA, Simas L, Osorio-de-Castro CGS, Ventura M. A judicialização da saúde e os novos desafios da gestão da assistência farmacêutica. Cien Saude Colet 2010; 15(5):2405-2414.

55. Santos-Pinto CDB, Ventura M, Pepe VLE, Osorio-deCastro CGS. Novos delineamentos da Assistência Farmacêutica frente à regulamentação da Lei Orgânica da Saúde. Cad Saúde Pública 2013; 29(6):1056-1058.

56. Santos-Pinto CDB, Costa NR, Osorio-de-Castro CGS Quem acessa o Programa Farmácia Popular do Brasil? Aspectos do fornecimento público de medicamentos. Cien Saude Colet 2011; 16(6):2963-2973.

57. Pereira MA. Programa farmácia popular no Brasil: uma análise sobre sua relação com o Complexo Econômico-Industrial da Saúde e os programas estratégicos do Governo Federal [dissertação]. Rio de Janeiro: Escola Nacional de Saúde Pública Sérgio Arouca; 2013.

58. Barros SG, Vieira-da-Silva LM. A terapia antirretroviral combinada, a política de controle da Aids e as transformações do Espaço Aids no Brasil dos anos 1990. Saúde Debate 2017; 41(n. esp. 3):114-128. 
59. Fedatto MS. Epidemia da AIDS e a Sociedade Moçambicana de Medicamentos: análise da cooperação brasileira. Cien Saude Colet 2017; 22(7):2295-2304.

60. Dubitzky W, Wolkenhauer O, Yokota H, Cho K-H, editores. Encyclopedia of Systems Biology. New York: Springer; 2013.

Artigo apresentado em 15/04/2020

Aprovado em 08/06/2020

Versão final apresentada em 10/06/2020 